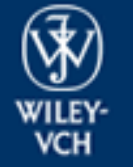

Fuel Cells

VCH

\title{
Innovative Perfluoropolyether-Functionalized Gas Diffusion Layers with Enhanced Performance in Polymer Electrolyte Membrane Fuel Cells
}

\begin{tabular}{|r|l|}
\hline Journal: & Fuel Cells \\
\hline Manuscript ID & fuce.201900169.R2 \\
\hline Wiley - Manuscript type: & Original Research Paper \\
\hline Date Submitted by the & 21 -Jan-2020 \\
\hline Complete List of Authors: & $\begin{array}{l}\text { Latorrata, Saverio; Politecnico di Milano, Chemistry, Materials and } \\
\text { Chemical Engineering } \\
\text { Sansotera, Maurizio; Politecnico di Milano } \\
\text { Gola, Massimo; Politecnico di Milano } \\
\text { Gallo Stampino, Paola; Politecnico di Milano, Chimica, Materiali e } \\
\text { Ingegneria Chimica G. Natta } \\
\text { Navarrini, Walter; Politecnico di Milano } \\
\text { Dotelli, Giovanni; Politecnico di Milano }\end{array}$ \\
\hline Keywords: & $\begin{array}{l}\text { PEM Fuel Cell, superhydrophobic coatings, gas diffusion layer, } \\
\text { perfluoropolyether, Water Management }\end{array}$ \\
\hline
\end{tabular}

\section{SCHOLARONE \\ Manuscripts}




\section{Innovative Perfluoropolyether-Functionalized Gas Diffusion Layers with Enhanced \\ Performance in Polymer Electrolyte Membrane Fuel Cells}

Saverio Latorrata ${ }^{1}$, Maurizio Sansotera ${ }^{1}$, Massimo Gola ${ }^{1}$, Paola Gallo Stampino ${ }^{1}$, Walter Navarrini ${ }^{1}$, Giovanni Dotelli ${ }^{1}$

${ }^{1}$ Department of Chemistry, Materials and Chemical Engineering "Giulio Natta", Politecnico di Milano, piazza Leonardo da Vinci 32, 20133 Milan (Italy)

Corresponding author:

Saverio Latorrata

e-mail: saverio.latorrata@polimi.it 


\begin{abstract}
In this work, perfluoropolyether (PFPE) functionalization was used as hydrophizing treatment for gas diffusion layers (GDLs) in polymer electrolyte membrane fuel cells (PEMFCs), instead of standard PTFE coatings, aiming to enhance the hydrophobicity of the gas diffusion media and to reduce the mass transfer limitations in the final device. Carbon cloth diffusion layers and carbon black were functionalized by decomposition of a PFPE peroxide. PFPE-functionalized carbon black was employed in the preparation of an ink suitable for obtaining microporous layers (MPLs) by deposition onto macroporous backing layers. Dual-layer gas diffusion media showing superhydrophobic behavior due to different hydrophobizing treatments were compared with conventional PTFE-based materials, by testing in a single PEMFC working at two different temperatures and at low and high relative humidity conditions. Such tests demonstrated improved performances over conventional GDLs for pure PFPE-based samples in terms of both overall electrical performance and reduced diffusive limitations in high current density conditions. The maximum output power achieved with the novel PFPE-based compounds was $460 \mathrm{~mW}$ $\mathrm{cm}^{-2}$ at $80{ }^{\circ} \mathrm{C}$ and $\mathrm{RH} 100 \%$ while the best improvement $(10 \%)$ with respect to conventional GDLs was realized at $80{ }^{\circ} \mathrm{C}$ and $\mathrm{RH} 60 \%$.
\end{abstract}

Keywords: PEM fuel cell; superhydrophobic coating; perfluoropolyethers; gas diffusion layer; water management 


\section{Introduction}

The expected future depletion of fossil fuels together with the growing attention to environmental issues has been leading to a considerable development of alternative forms of energy. Polymer electrolyte membrane fuel cells (PEMFCs) are one of the most promising clean-energy generators for both portable and non-portable devices due to their high efficiency, low working temperature and zero pollutant emissions [1-3]. In order to make such systems completely competitive with other forms of energy generators, costs of materials have to be reduced, overall durability enhanced and some technical issues solved. In this perspective, water flooding in porous gas diffusion layers (GDLs) is a critical aspect which can affect the performance of the whole device [4]. Indeed, under severe operating conditions, i.e. high humidity levels or high current densities, a huge amount of water, if not properly discharged out from the cell, can block pores of carbonaceous materials or bipolar plates channels thus hindering reactant gases to reach the active area of the membrane electrode assembly (MEA) and causing a sudden cell voltage loss. Therefore, a proper water management in PEMFCs is required and this task is accomplished by achieving GDLs hydrophobicity.

GDLs play a fundamental role in several issues of PEMFCs, such as supplying gaseous reactants homogeneously to the electrodes active area, removing the formed water out of the cell, electrically connecting the electrode to the bipolar plate and providing mechanical support to MEA. Indeed, it has been largely proved that using GDLs drives to a remarkable improvement of device performances [4-7]. The GDL typically consists of a macroporous substrate (MPS) made of carbon cloth or carbon paper and a thin coating, termed microporous layer (MPL), deposited onto the former. MPL is usually prepared starting from an ink based on carbon nanoparticles mixed with a hydrophobic polymeric agent [4-10]. The hydrophobizing treatment of GDLs with appropriate low surface energy agents allows the removal of water produced by the fuel cell $[5,11,12]$. Typically, polytetrafluoroethylene 
(PTFE) has been employed as hydrophobic agent, for both backing and microporous layers [4, 5], but several alternatives have been also studied aiming to enhance performance of the fuel cell. In this respect, GDLs have been treated with tetrafluoromethane $\left(\mathrm{CF}_{4}\right)$, trifluoromethane $\left(\mathrm{CHF}_{3}\right)$ or sulfur hexafluoride $\left(\mathrm{SF}_{6}\right)$ plasma [13, 14], polyvinylidene fluoride (PVDF) [15], fluorinated ethylene propylene (FEP) [16-19], perfluoropolyether derivatives (PFPE) $[12,19,20]$, perfluoralcoxy (PFA) [19], electrochemically reduced diazonium salts [21] and silicone nanolayers [11]. The dipcoating process is the most used method for the deposition of hydrophobizing agents [5, 16, 18, 22], even though other techniques, such as chemical grafting [12, 21] or dry plasma deposition process $[11,13,14]$ have been also exploited in order to overcome the issues related to wet processes. Hydrophobic polymer distribution strictly depends on the drying process, which usually represents a limiting step for the uniformity of the final coating. Moreover, especially for PTFE-treated GDLs supports, polymeric layers can represent a barrier to gas diffusion and electrons flux, reducing gas permeability and electric conductivity [23]. Many research works proved that depositing MPLs onto macroporous supports enhances water management, driving to higher electrochemical performances $[4,5,9,24-28]$. Indeed, due to its microporosity, MPL removes water from the catalytic layer to the bipolar plate channels lowering water saturation level [29-32]. A standard ink formulation for MPLs contains carbon black (CB) and polytetrafluoroethylene (PTFE): the former is usually dispersed in aqueous or organic solvents by using proper dispersants, the latter is used as both hydrophobic agent and binder. The ink is deposited onto one side of a pre-hydrophobized MPS and the so-formed dual-layer GDL is heat treated to evaporate solvents and to sinter the hydrophobic polymer [5].

A well-established methodology that confers stable highly hydrophobic properties to carbonaceous substrates is based on the covalent linkage of perfluoropolyether (PFPE) chains through the chemical treatment with PFPE peroxides [33]. The functionalization 
with PFPE chains achieved additional advantages if compared to PTFE-hydrophobization, such as a more durable water repellency during the fuel cell lifetime and a better gas diffusion due to lower loadings of polymer as well as to the typical gas permeability of PFPEs [34].

In this work, a spray deposition procedure for the preparation of a microporous layer (MPL) based on PFPE-functionalized CB was developed and a dual-layer GDL was accordingly prepared. The main difference between PTFE and PFPE is that the former is in solid state in the temperature range of a working fuel cell, while the latter is liquid in the same conditions. For this reason, the convenience of using a binder for the assembly of functionalized $\mathrm{CB}$ on PFPE-grafted GDLs was also investigated. The amorphous perfluorinated polymer Hyflon $A D^{\circledR}$, that is a random copolymer of tetrafluoroethylene (TFE) and 2,2,4-trifluoro-5-trifluoromethoxy-1,3-dioxole (TTD), was identified as a possible binder for CB and it was firstly applied on both a bare MPL and a GDL support to understand its influence on a dual-layer assembly. The wettability and the morphology of all the dual-layer GDLs prepared with PFPEs as well as with Hyflon $A^{\circledR}$ were investigated.

Fluorinated polymers are widely recognized as highly hydrophobic materials and their typical wettability can be transferred to the surface of carbon-based materials by the application of a fluoropolymer-based coating $[35,36]$. In ink formulation, the polymeric material that forms the film is usually referred as binder and the small particles added to the formulation in order to affect the physical properties of the resulting coating are indicated as fillers [37]. Thus, in the inks used for GDLs preparation, peroxidic PFPE and Hyflon $A D^{\circledR}$ were employed as hydrophobic binders, while $C B$ was used as conductive filler.

The peroxidic moieties along the molecular structure of the PFPE peroxide produce PFPE radicals by thermal decomposition and the perfluorinated radicals chemically functionalize 
the carbonaceous structure of CC and CB [34]. In a previous research, it was observed that the conductive properties of $\mathrm{CB}$ and $\mathrm{CC}$ treated with PFPE peroxide were maintained, even if their surfaces became superhydrophobic due to the functionalization [12]. However, PFPEs are characterized by low intermolecular forces and great chain flexibility, which overall result in poor mechanical properties which are not enough to sustain the MPL on the MPS of the GDL [38]. Thus, detachment of the MPL from the substrate can be observed by using PFPEs as sole binders. A polymeric blend of PFPE peroxide and Hyflon $A D^{\circledR}$ can combine the chemical properties of the former and the mechanical behavior of the latter, producing resistant coatings with thickness in the submicron range [39]. A treatment employing only Hyflon $A D^{\circledR}$ was also tested for benchmarking purposes. Spraying deposition was employed because it is considered as the most common application technique for fluoropolymer coatings [37].

The electrical behaviors of fuel cells containing the dual-layer GDLs of this work were assessed by polarization curves, power density curves and impedance spectroscopy; moreover they were compared to conventionally prepared PTFE-based GDLs.

\section{Experimental}

\subsection{Materials}

The MPS for the dual-layer GDLs prepared in this study was a commercial carbon cloth (S5 purchased by SAATI S.p.A., Italy). The CB used to obtain the MPLs was a highly conductive, commercially available graphitic CB with high surface area (Cabot Vulcan ${ }^{\circledR}$ XC72R). The peroxidic PFPE was a high molecular weight Fomblin ${ }^{\circledR}$ Z PFPE (Solvay Specialty Polymers) with linear structure in which the monomeric units $\left(\mathrm{CF}_{2} \mathrm{CF}_{2} \mathrm{O}\right)_{m}$, $\left(\mathrm{CF}_{2} \mathrm{O}\right)_{n}$ and peroxidic units $(\mathrm{O})_{v}$ were randomly distributed along the polymer chain: $\mathrm{T}\left(\mathrm{CF}_{2} \mathrm{CF}_{2} \mathrm{O}\right)_{m}\left(\mathrm{CF}_{2} \mathrm{O}\right)_{n}(\mathrm{O})_{V} \mathrm{~T}^{\prime}$. The chemical characteristics of the peroxidic PFPE are here reported: average molecular weight around 29,500 u, ratio 1.15 between perfluoroethylene 
oxide $(m)$ and perfluoromethylene oxide $(n)$ groups, peroxidic content $(v)$ of 1.32 wt.\%, average equivalent molecular weight $1,200 \mathrm{~g} \mathrm{eq}^{-1}$, and $\mathrm{CF}_{3}, \mathrm{COF}, \mathrm{CF}_{2} \mathrm{COF}$ as terminals ( $T, T^{\prime}$ ). Hyflon $A D^{\circledR}$ (Solvay Specialty Polymers) is a random copolymer of TFE and TTD and it has the typical hydrophobic and insulating properties of perfluorinated polymers. Galden ${ }^{\circledR}$ HT55 (Solvay Specialty Polymers) is a mixture of linear PFPE fluids with boiling point at $55^{\circ} \mathrm{C}$ and it was employed as solvent.

\subsection{GDL Preparation}

Three fluorinated inks were prepared by suspending CB $(0.5 \mathrm{wt} . \%)$ in a perfluoropolymeric solution with Galden ${ }^{\circledR}$ HT55 as solvent: the first solution contained 0.5 wt.\% of linear peroxidic PFPE (i), the second 0.5 wt.\% of peroxidic PFPE and 0.01 wt.\% of Hyflon AD $^{\circledR}$ (ii) and the third 0.01 wt.\% of Hyflon $\mathrm{AD}^{\circledR}$ (iii). Three prototypes of dual-layer GDLs hydrophobized with perfluoropolymers were realized by spraying different carbonaceous inks on carbon cloth $(\mathrm{CC})$ in order to obtain the MPL on the macroporous substrate. The spraying time varied depending on the ink: $4 \mathrm{~s}$ for the PFPE-based ink (i), $8 \mathrm{~s}$ for the ink containing both peroxidic PFPE and Hyflon $A D^{\circledR}$ (ii) and $4 \mathrm{~s}$ for the Hyflon-based ink (iii).

The dual-layer GDLs prepared by using the two inks containing peroxidic PFPE (i.e. inks (i) and (ii)) were dried at $40{ }^{\circ} \mathrm{C}$ for $2 \mathrm{~h}$ under $\mathrm{N}_{2}$ flux for solvent evaporation and thermally treated starting from $150{ }^{\circ} \mathrm{C}$ to $200{ }^{\circ} \mathrm{C}$, increasing the temperature stepwise at the rate of $15^{\circ} \mathrm{C} \mathrm{h}^{-1}$ and then heating at $200{ }^{\circ} \mathrm{C}$ for $4 \mathrm{~h}$. The reactivity of peroxidic PFPE moieties, which decompose generating radical species with a half-life of $30 \mathrm{~min}$ in a range of temperatures between 140 and $250^{\circ} \mathrm{C}$, was considered for defining this thermal treatment $[40,41]$. After the thermal treatment, the backing layer of these GDLs was dipped in a 2 wt.\% solution of peroxidic PFPE in Galden $^{\circledR}$ HT55 in order to achieve a uniform PFPE functionalization of the backing layer. Thereafter, these GDLs underwent the same thermal treatment previously described for PFPE peroxide decomposition. At the end of the 
thermal treatment, the GDLs were rinsed with Galden ${ }^{\circledR}$ HT55 and then with deionized water. Finally, they were dried under vacuum at $200{ }^{\circ} \mathrm{C}$ for $6 \mathrm{~h}$.

The dual-layer GDL treated with Hyflon $A D^{\circledR}$ was realized in a two steps procedure: firstly, the $\mathrm{CC}$ was dipped in a solution of pure Hyflon $\mathrm{AD}^{\circledR}\left(8.5\right.$ wt.\%) in Galden ${ }^{\circledR} \mathrm{HT} 55$ and it was dried at $70{ }^{\circ} \mathrm{C}$ for $20 \mathrm{~min}$; secondarily, the MPL was prepared by spraying the Hyflonbased ink (i.e. ink (iii)) on $\mathrm{CC}$ and it was dried at $70{ }^{\circ} \mathrm{C}$ for 20 min under $\mathrm{N}_{2}$ flux for solvent evaporation.

For the sake of comparison, a conventional dual-layer GDL based on the same MPS and on PTFE and Vulcan XC72R carbon black as MPL components, developed in our laboratory and reported in the reference [19], was used as benchmark. The deposited MPL showed a thickness around $50-70 \mu \mathrm{m}$ and a total porosity of $69 \%$ with a mean pore diameter of $53.3 \mathrm{~nm}[19]$.

\subsection{Characterization}

The contact angle instrument was a Data Physics OCA 150 and the software was SCA20 version 2.3.9. build 46. The contact angles were measured by depositing water droplets directly on the sample surface. Static contact angle measurements were repeated 10 times on each sample in order to obtain average values. In the case of superhydrophobic surfaces and particularly with surfaces characterized by a contact angle above $170^{\circ}$, the water contact angle evaluation results underestimated because of the shape deformation of the droplets under their own weight.

The scanning electron microscopy (SEM) observation of the samples was performed by using a Zeiss EVO50 EP scanning electron microscope. The samples were analyzed without applying conductive coating or surface etching. The SEM parameters were as follows: working distance of $7.0 \mathrm{~mm}$, beam current of $20 \mathrm{pA}$, acceleration voltage of 17.0$17.5 \mathrm{kV}$ and different magnifications with respect to a 1024 pixel $x 768$ pixel image. 
GDLs were tested electrochemically in a $23 \mathrm{~cm}^{2}$ lab-scale fuel cell at $60{ }^{\circ} \mathrm{C}$ and $80{ }^{\circ} \mathrm{C}$ and at two values of relative humidity $(80-100 \%$ and $80-60 \%$ at the anode and the cathode, respectively). The same kind of GDL was used for both anode and cathode. A commercial catalyst coated membrane (CCM, supplied by Baltic Fuel Cells) was employed as MEA; electrolyte was a $50 \mu \mathrm{m}$ thick Nafion ${ }^{\mathrm{TM}}$ membrane and $\mathrm{Pt}$ was the active catalytic phase, with a loading of 0.2 and $0.4 \mathrm{mg} \mathrm{cm}^{-2}$ at the anode and the cathode, respectively. Supplied volumetric flow rates were 0.25 and $1.0 \mathrm{NL} \mathrm{min}^{-1}$ for hydrogen and air, respectively, corresponding to stoichiometric ratios of 1.2 for hydrogen and 2 for air, calculated for a current of 30 A. Polarization measurements and electrochemical impedance spectroscopy (EIS) were performed under galvanostatic conditions in the current density range from OCV to $1.32 \mathrm{~A} \mathrm{~cm}^{-2}$, with steps of $0.088 \mathrm{~A} \mathrm{~cm}^{-2}$. EIS was carried out by using a frequency response analyzer (FRA, Solartron 1260) over a frequency range of $0.5 \mathrm{~Hz}-1 \mathrm{kHz}$; ten points per decade were acquired. Each spectrum was obtained as the average of five spectra per each value of current density. The collected spectra were modeled by means of equivalent circuits in order to get the contributions to potential losses, namely activation polarization, ohmic losses and concentration polarization [42]; this was accomplished by using the ZView ${ }^{\circledR}$ software (Scribner Associates). Such equivalent circuits are reported in Supplementary Materials and were developed by modifying the models used in literature $[43,44]$. The equivalent circuit used for the spectra obtained at low current density values consists of a resistance representing the cell overall ohmic resistance, also referred to as HFR (high frequency resistance), in series with two parallel resistance/constant phase element circuits modeling the anodic and the cathodic activation polarization (i.e. charge transfer resistance on the electrode surfaces). While anodic activation polarization can be sometimes negligible, cathodic one is always visible and higher than anodic contribution due to the sluggish kinetics of the oxygen reduction half-reaction. For impedance spectra collected at medium and at high current density, one more parallel circuit is added in 
series with cathodic charge transfer resistance in order to model mass transfer limitations (i.e. diffusion resistances) which arise upon increasing current density because of a higher amount of produced liquid water. Constant phase elements (CPE) were employed, instead of pure capacitors, to consider the capacitive losses which take place in non-ideal porous electrodes [32, 45].

A preliminary evaluation of durability was also performed on the standard PTFE-based GDLs and on the best performing PFPE-based ones. This was accomplished keeping the fuel cell at constant current density $\left(0.5 \mathrm{~A} \mathrm{~cm}^{-2}\right)$ for 500 hours at $80{ }^{\circ} \mathrm{C}$ and $\mathrm{RH} 80-100 \%$, carrying out electrical tests with polarization curves recorded every 100 hours.

An ex-situ mechanical accelerated stress test (AST) was also performed on the same samples in order to have a quick preliminary evaluation about the durability of the prepared components in terms of mechanical resistance without performing continuous tests for thousands of hours. Indeed, it has been proved that the mechanical degradation is the most detrimental stressor for the GDL mainly due to detachment of the MPL surface carbon that can be induced by both continuous flow of the gaseous reactants and the presence of water [44].

The GDLs were assembled in a dummy cell featuring a $210 \mu \mathrm{m}$ thick Teflon membrane as a separator without catalyst layers in order to avoid any possible chemical stress on the samples. Air was fed continuously for 500 hours on each side of the cell with a twofold flow rate compared to the one employed for conventional tests $\left(0.5 \mathrm{NL} \mathrm{min}^{-1}\right.$ at the anode and $2 \mathrm{NL} \min ^{-1}$ at the cathode) to promote mechanical degradation.

\section{Results and Discussion}

\subsection{Morphological Characterization}

The morphology of the dual-layer GDLs realized with the fluoropolymer-based inks was resolved at different magnifications and the corresponding images at low and high 
resolution were reported in Figure 1. The GDL prepared with the PFPE-based ink (i) showed a homogeneous deposition of the MPL on the MPS (Figure 1A). At high magnification, it was observed that $\mathrm{CB}$ particles were deposited on the $\mathrm{CC}$ generating granular structures (Figure 1B). Thus, marginal ohmic effects can be expected due to a good electrical continuity between the GDL and the catalytic layer. Moreover, micrometric interstices between CC fibers were maintained, supposedly slightly affecting the homogeneity of gas diffusion into the GDL (Figure 1B). The ink (ii), which contains both peroxidic PFPE and Hyflon $A D^{\circledR}$, generated a cumbersome MPL (Figure 1C) in which a polymeric barrier was formed by including many fibers, covering the empty spaces between them and decreasing the porosity suitable for gases diffusion (Figure 1D). The morphology of the MPS obtained by spraying the Hyflon-based ink (iii) resulted similar to that shown by ink (i) (Figure 1E). However, an outlined fluoropolymeric layer can be observed between the fibers (Figure 1F). The contact angle measurements with water showed that the typical highly hydrophobic properties of fluorinated materials were transferred to the carbon-based surfaces of the GDLs by using all the fluoropolymer-based inks (Table 1). Contact angle values around $170^{\circ}$, thus exceeding the threshold of superhydrophobicity (i.e. $150^{\circ}$ ), were observed for all these samples. The hydrophobic effects due to the treatment with inks (i), (ii) and (iii) resulted also higher than that observed for the treatment with PTFE [18]. The transfer of superhydrophobic properties to MPL and MPS of GDLs due to the use of hydrophobizing agents is commonly considered an improvement of the water management inside the fuel cell.

\subsection{Electrochemical Characterization}

Polarization and power density curves obtained with fuel cells assembled with couples of the novel GDLs prepared in this work are reported in Figure 2 and they were compared with those measured with a conventional PTFE-based sample. In each electrochemical 
testing, the employed GDLs for both anode and cathode underwent the same hydrophobizing treatment.

GDLs hydrophobized with PFPE resulted more effective than those treated with PTFE: indeed, in each condition of temperature and humidity, an improvement of the electrical performances was observed at medium-high current density values (Figure 2). This is evident in terms of both polarization and, particularly, maximum power density reached. It is worth to notice that the performances of PFPE-functionalized GDLs seem slightly affected by temperature and relative humidity variations. In fact, polarization curves show very similar trend and values in the concentration polarization region in all the operating conditions (Figure 2): therefore, the water management with these GDLs remains almost constant regardless of temperature and humidity. This result can be ascribed to the highly hydrophobic properties induced by the perfluorinated chains and to the minimal influence on the electrical conductivity typical of PFPE functionalization [41]. As a matter of fact, for these PFPE-functionalized GDLs, power density peaks resulted shifted towards higher current densities at each operating condition (Figure 2).

Hyflon $A D^{\circledR}$-treated GDLs showed very similar behaviors compared to GDLs hydrophobized with PTFE (Figure 2), obtaining comparable effects by using lower amounts of polymer. Indeed, thanks to their high hydrophobicity, Hyflon-functionalized GDLs, similarly to those treated with PFPE, allowed an efficient mass transport across the macro- and the microporous layers because the water produced was easily removed and flooding was avoided.

Instead, the GDLs treated with the mixture PFPE-Hyflon showed, in all conditions of temperature and humidity, the highest slopes of polarization curve in the ohmic zone (Figure 2). Therefore, this kind of treatment was not beneficial for the electrical performances of the fuel cell, likely due to its higher dielectric content which might have significantly lowered the conductivity. This effect emerged especially at low RH due to the 
lowered hydration of the electrolyte (Figure 2B and 2D) and it became maximally marked at $80{ }^{\circ} \mathrm{C}$ (Figure 2D) because at this temperature water evaporation was intensified decreasing further the proton conductivity.

Table 2 summarizes the above concepts, reporting maximum performances, in terms of power density obtained for all the testing conditions.

These measurements suggested that PFPE-based dual-layer GDL is a promising candidate which can replace PTFE-based conventional materials in real applications because it allowed the achievement of the highest output power densities in all the operating conditions. Indeed, PFPE-functionalized GDL showed an increase of maximum power density of $4.5 \%$ to $10 \%$ compared to standard GDLs with PTFE. The operating condition at high temperature and high cathodic humidity allowed the best performances, because the water management in the fuel cell did not suffer of high humidity due to the high hydrophobicity of the employed polymer. Hyflon $A D^{\circledR}$-hydrophobized GDL performed with maximum of power density similar to that of PTFE: approximately around $3 \%$ higher in dry condition at $80{ }^{\circ} \mathrm{C}$ and $3 \%$ lower in wet condition at $80{ }^{\circ} \mathrm{C}$ and in both the humidity conditions at $60{ }^{\circ} \mathrm{C}$. These analogous performances can be ascribed to the solid nature of both Hyflon $A D^{\circledR}$ and PTFE, which facilitates the formation of solid barriers inside the GDL including many fibers and covering the empty spaces between them. However, it can be expected that an optimization of the formulation of ink (iii), exploiting the amorphous nature of Hyflon $A{ }^{\circledR}$, improves the performances obtained with Hyflon-hydrophobized GDLs.

As introduced before, EIS was performed in order to characterize the prepared materials by distinguishing the contribution of activation polarization, ohmic losses and concentration polarization. General trends and shapes were kept for all the GDL samples at each operating condition. The equivalent circuits for spectra modeling have been discussed in paragraph 2.3 and reported as Supplementary Material. 
As an example, EIS spectra of a working fuel cell assembled with PFPE-treated dual-layer GDLs, at $60{ }^{\circ} \mathrm{C}$ and high cathodic relative humidity, at low and high current densities are reported in Figure 3. The arc diameters related to the activation polarization resistance decreased upon increasing current density, while the high frequency resistance, i.e. the overall ohmic resistance, remained constant. At high values of current density (Figure 3B) spectra were split in two well-distinguished arcs because low frequency contributions due to mass transfer were clearly present. Such contributions are mainly due to cathodic losses induced by water production. Therefore, the complete equivalent circuit considering mass transport contribution was employed to get mass transfer resistances. It is evident that an increase in current density drove to an increase in mass transfer resistance since more water was produced and consequent diffusive limitations arose. It is worth noting that the total activation polarization is the sum of anodic and cathodic contributions. Hereafter, only ohmic and mass transfer resistances will be discussed, because they are the parameters mostly influenced by GDLs features and morphology. Indeed, charge transfer resistance is related to the efficiency of the catalytic layer, which, in our case, is commercial and fixed for all the tests. Values obtained for ohmic resistance $\left(R_{\Omega}\right)$ and mass transfer resistance $\left(R_{m t}\right)$, sometimes referred to as diffusion resistance, are reported in Figure 4 and Figure 5, respectively. It seems that the change in relative humidity influenced the ohmic resistance much more clearly than temperature variation. Indeed, when temperature was fixed, at both 60 and $80{ }^{\circ} \mathrm{C}$, an increase in cathodic $\mathrm{RH}$ determined a decrease of the mean ohmic resistance for all the samples. This result was expected because a higher content of water can improve membrane proton conductivity, reducing consequently the overall ohmic resistance. However, this behavior seems to be sharper for GDLs prepared with ink (ii), which contains both PFPE and Hyflon, and it is likely due to the thick fluoropolymeric barrier observed in the MPL. PTFE-based samples showed slightly lower values than both PFPE and Hyflon, even if this difference was not 
immediately noticeable from the observation of the polarization curves. Anyway, such light differences in ohmic resistance, likely due to the slight differences in GDLs wettability, can be considered negligible because the slopes of the different polarization curves in the ohmic zone (i.e. the linear section at medium current density) kept constant and the overall electrical performances of PTFE-based conventional GDLs resulted a bit lower than those of the innovative GDLs treated with PFPE, Hyflon $\mathrm{AD}^{\circledR}$ and their blend.

It was confirmed that PFPE-Hyflon sample prepared with ink (ii) performed worse than the other samples and that the parameter which negatively affected performance is $R_{\Omega}$ itself, particularly at $80{ }^{\circ} \mathrm{C}$ and cathodic $\mathrm{RH} 60 \%$ (Figure 4D), when less water is present due to the combination of low cathodic $\mathrm{RH}$ and high temperature (i.e. higher evaporation rate); indeed, its higher dielectric content can likely play the determining role in increasing the overall ohmic resistance.

Figure 5 reports mass transfer resistance $\left(R_{m t}\right)$, sometimes referred to as diffusion resistance, obtained at different current densities. The general expected trend, which shows an increase of such parameter upon increasing current densities, was obtained. This is due to a higher and faster water production which makes the reactants reaching of the active sites more difficult. GDLs treated with PTFE exhibited the highest $R_{m t}$ values and high cathodic $\mathrm{RH}$ resulted to be the worst condition, especially at $60{ }^{\circ} \mathrm{C}$. Indeed, the combination of high humidity and a lower temperature reduced water local evaporation and, therefore, generated the highest diffusion limitations. New PFPE-based materials, both with and without Hyflon $\mathrm{AD}^{\circledR}$ binder showed restrained mass transfer resistances at each operating conditions, even at high current densities. This behavior could be ascribed to the extremely low wettability induced by the functionalization of MPLs with these amorphous perfluorinated polymers. Even PFPE-Hyflon sample showed very low diffusive resistances, in some conditions better than PFPE-based GDLs. Thus, it would seem that it can guarantee a very efficient water management at any operating conditions. Moreover, a 
higher total porosity (77 \% vs. $69 \%$ ) together with a slightly lower mean pore diameter (48.8 nm vs. $53.3 \mathrm{~nm}$ ) in the micro-porous region was found in a previous work for PFPEbased samples compared to conventional PTFE-ones [19]. Such parameters can play a role in improving the capillary condensation and the velocity of water removal from the GDL towards the bipolar channels of the fuel cell.

This behavior can confirm that ohmic resistance was the penalizing parameter for PFPEHyflon GDL. The high content of fluorinated hydrophobic agents was effective in enhancing the water management ability but it resulted detrimental for the overall resistance and, therefore, for the total electrical performance.

\subsection{Durability evaluation}

Figure 6 shows polarization curves obtained upon constant current durability tests for fuel cells assembled with the fresh PFPE- and PTFE-based GDLs. An almost perfect overlapping of the curves obtained every 100 hours of tests can be observed, denoting a satisfying durability of the prepared GDLs. Only a very slight voltage drop can be noticed on the polarization curve related to PFPE sample (Fig. 6A) upon 500 hours; this may be ascribed to an increase in diffusive limitations due to an accumulation of water. However, it is worth noting that real PEM fuel cells systems generate electricity in the ohmic region and in that zone all the curves show the same voltage value and the same global cell efficiency, being such parameter directly proportional to the output voltage [54]. This is also the reason why we performed such tests at $0.5 \mathrm{~A} \mathrm{~cm}^{-2}$.

Nevertheless, it must be considered that this test is just a preliminary indication about durability since longer or ad-hoc accelerated experiments would need to be more accurate in forecasting the real behavior of such systems. Therefore, we carried out mechanical accelerated stress tests (AST) and Figure 7 reports the polarization and power density curves upon 500 hours of these experiments compared to those obtained upon 500 hours 
of the constant current test. Both samples exhibited a reduction in performance, even though this is not drastic and the potential value in the ohmic region is still acceptable to guarantee a suitable efficiency in real applications. The highest voltage loss is localized in the high current region, i.e. the concentration polarization zone, and it was likely induced by a more difficult water management upon stress tests due to partial loss of microporous material. Such considerations may be more evident by observing the trend of ohmic and especially of diffusion resistances (Figure 8) obtained by impedance spectroscopy as a function of current density. The change in the ohmic resistance (Figure 8A) upon ASTs is not significant whereas a clear increase of the mass transfer resistance (Figure 8B) is evident for both samples. This behavior can be related to a worsening of the capability of removing the generated water induced by MPL surface stresses due to mechanical ASTs and is consistent with findings of previous works [54]. However, even though the presence of PFPE caused for the diffusion resistance a greater variation at high current density compared to the non-stressed sample, the maximum value is still lower than the corresponding one exhibited by the conventional PTFE-based GDL.

\section{Conclusions}

In this work, novel dual-layer GDLs based on non-standard fluorinated hydrophobic agents were prepared, characterized and compared with conventional PTFE-treated dual-layer GDLs. Such new GDLs were obtained by making both macroporous backing layer and MPL hydrophobic. Particular attention was paid to the functionalization with PFPE of the carbon black used for the preparation of several inks for MPLs deposition. A binder, Hyflon $A D^{\circledR}$, was also used and the features of the resulting GDLs were evaluated.

The morphology of the dual-layer GDLs was studied by SEM analysis and all the samples showed a homogeneous deposition of the MPL on the MPS. In both pure PFPE- and Hyflon $\mathrm{AD}^{\circledR}$-treated GDLs, the MPL consisted of granular over-structures due to $\mathrm{CB}$ 
particles deposition, leaving micrometric interstices between the fibers of the MPS. In the GDL prepared with the binder blend of PFPE and Hyflon, a thick polymeric barrier including many fibers was observed. Superhydrophobic properties due to fluoropolymer hydrophobizing treatments, such as PFPE functionalization or impregnation with an amorphous perfluorinated polymer, were observed on all MPLs and MPSs of the GDLs.

Pure PFPE-based materials allowed the achievement of higher power densities than conventional GDLs hydrophobized with PTFE, while the addition of a Hyflon AD $^{\circledR}$-based binder resulted in worse performances due to higher dielectric features, mainly detrimental for the ohmic resistance.

The maximum power density achieved with the novel PFPE-based compounds was 460 $\mathrm{mW} \mathrm{cm}{ }^{-2}$ at $80{ }^{\circ} \mathrm{C}$ and $\mathrm{RH} 100 \%$ while the best improvement $(10 \%)$ with respect to conventional GDLs was obtained at $80^{\circ} \mathrm{C}$ and $\mathrm{RH} 60 \%$.

The innovative GDLs allowed the enhancement of water management in the fuel cell, significantly reducing mass transfer resistance at high current densities. Moreover, the well-known chemical-physical stability of these fluorinated materials can suggest a durability comparable to that obtainable with PTFE. Durability is crucial in this field and, therefore, further studies for benchmarking in this direction are highly recommended.

However, durability of the best performing PFPE-based and conventional PTFE-based GDLs was preliminarily assessed both through constant current experiments and accelerated stress tests. A slight increase in mass transport limitations was found for both stressed samples in the high current density region while constant current experiments did not cause any significant variation in the overall performance of the fuel cell. These promising perspectives could address future research towards such amorphous fluoropolymers for replacing conventional GDLs used nowadays. 


\section{References}

[1] R. Omrani, B. Shabani, Int. J. Hydrogen Energ. 2019, 44, 3834.

[2] Y. Wang, K. S. Chen, J. Mishler, S. C. Cho, X. C. Adroher, Appl. Energ. 2011, 88, 981.

[3] L. Carrette, K. A. Friedrich, U. Stimming, Fuel Cells 2001, 1, 5.

[4] R. Omrani, B. Shabani, Int. J. Hydrogen Energ. 2017, 42, 28515.

[5] S. Park, J. W. Lee, B. N. Popov, Int. J. Hydrogen. Energ. 2012, 37, 5850.

[6] Y. X. Wang, S. Al Shakhshir, X. G. Li, Appl. Energ. 2011, 88, 2168.

[7] A. Ozden, S. Shahgaldi, X. G. Li, F. Hamdullahpur, Renew. Energ. 2018, 126, 485.

[8] S. G. Kandlikar, M. L. Garofalo, Z. Lu, Fuel Cells 2011, 11, 814.

[9] M. J. Leeuwner, A. Patra, D. P. Wilkinson, E. L. Gyenge, J. Power Sources 2019, 423, 192.

[10] A. T. Najafabadi, M. J. Leeuwner, D. P. Wilkinson, E. L. Gyenge, Chem. Sus. Chem. 2016, 9, 1689.

[11] T. J. Ko, S. H. Kim, B. K. Hong, K. R. Lee, K. H. Oh, M. W. Moon, Acs Appl. Mater. Inter. 2015, 7, 5506.

[12] M. Gola, M. Sansotera, W. Navarrini, C. L. Bianchi, P. G. Stampino, S. Latorrata, et al., J. Power Sources 2014, 258, 351.

[13] Y. H. Pai, J. H. Ke, H. F. Huang, C. M. Lee, Z. Jyh-Myng, F. S. Shieu, J. Power Sources 2006, 161, 275.

[14] C. M. Lee, Y. H. Pai, J. M. Zen, F. S. Shieu, Mater Chem Phys 2009, 114, 151.

[15] S. Park, S. Kim, Y. Park, M. Oh, Journal of Physics: Conference Series 2009, 165, 012046.

[16] C. Lim, C. Y. Wang, Electrochim. Acta 2004, 49, 4149.

[17] S. B. Park, Y. I. Park, Int. J. Precis. Eng. Man. 2012, 13, 1145. 
[18] S. Latorrata, P. G. Stampino, C. Cristiani, G. Dotelli, Int. J. Hydrogen Energ. 2014, 39,5350 .

[19] S. Latorrata, R. Balzarotti, P. G. Stampino, C. Cristiani, G. Dotelli, M. Guilizzoni, Prog. Org. Coat. 2015, 78, 517.

[20] R. Balzarotti, S. Latorrata, P. G. Stampino, C. Cristiani, G. Dotelli, Energies 2015, 8, 7070 .

[21] Y. R. J. Thomas, A. Benayad, M. Schroder, A. Morin, J. Pauchet, Acs Appl. Mater. Inter. 2015, 7, 15068.

[22] P. G. Stampino, S. Latorrata, D. Molina, S. Turri, M. Levi, G. Dotelli, Solid State Ionics 2012, 216, 100.

[23] S. Park, J. W. Lee, B. N. Popov, J. Power Sources 2008, 177, 457.

[24] T. Kitahara, H. Nakajima, K. Mori, J. Power Sources 2012, 199, 29.

[25] T. Kim, S. Lee, H. Park, Int. J. Hydrogen Energ. 2010, 35, 8631.

[26] R. B. Ferreira, D. S. Falcao, V. B. Oliveira, A. M. F. R. Pinto, Electrochim. Acta 2017, 224, 337.

[27] M. J. Leeuwner, D. P. Wilkinson, E. L. Gyenge, Fuel Cells 2015, 15, 790.

[28] J. Lee, H. Liu, M. G. George, R. Banerjee, N. Ge, S. Chevalier, et al., J. Power Sources 2019, 422, 113.

[29] J. H. Chun, D. H. Jo, S. G. Kim, S. H. Park, C. H. Lee, S. H. Kim, Renew. Energ. 2012, 48, 35 .

[30] S. Park, B. N. Popov, Electrochim. Acta 2009, 54, 3473.

[31] P. Shrestha, D. Ouellette, J. Lee, N. Ge, A. Kai, C. Wong, et al., Adv. Mater. Interfaces 2019, 6 .

[32] A. K. C. Wong, N. Ge, P. Shrestha, H. Liu, K. Fahy, A. Bazylak, Appl. Energ. 2019, 240,549 . 
[33] M. Sansotera, C. L. Bianchi, G. Lecardi, G. Marchionni, P. Metrangolo, G. Resnati, et al., Chem. Mater. 2009, 21, 4498.

[34] M. Sansotera, W. Navarrini, M. Gola, G. Dotelli, P. G. Stampino, C. L. Bianchi, Int. J. Hydrogen Energ. 2012, 37, 6277.

[35] M. Sansotera, M. Gola, G. Dotelli, W. Navarrini in Fluorinated Polymers, Vol. 2 (Eds. B. Ameduri), The Royal Society of Chemistry, Cambridge, 2017, pp. 158.

[36] M. Sansotera, M. Gola, W. Navarrini in New Fluorinated Carbons: Fundamentals and Application (Eds. O. V. Boltalina, T. Nakajima, A. Tressaud), Elsevier, Amsterdam, 2017, pp. 361.

[37] L. W. McKeen. Fluorinated coatings and finishes handbook, William Andrew Publishing, Norwick, 2006, pp. 395

[38] D. Sianesi, G. Marchionni in Organofluorine chemistry - Principles and commercial application (Eds. R. E. Banks, B. E. Smart, J. C. Tatlow), Plenum Press, New York, 1994, pp. 57.

[39] R. R. Tiwari, Z. P. Smith, H. Q. Lin, B. D. Freeman, D. R. Paul, Polymer 2014, 55, 5788.

[40] P. A. Guarda, E. Barchiesi, G. Fontana, S. Petricci, M. Pianca, G. Marchionni, J. Fluorine Chem. 2005, 126, 141.

[41] M. Sansotera, W. Navarrini, L. Magagnin, C. L. Bianchi, A. Sanguineti, P. Metrangolo, et al., J. Mater. Chem. 2010, 20, 8607.

[42] X. Z. Yuan, C. Song, H. Wang, J. Zhang, Electrochemical Impedance Spectroscopy in Pem Fuel Cells: Fundamentals and Applications, Springer, London, 2010, pp. 420.

[43] M. Boillot, C. Bonnet, N. Jatroudakis, P. Carre, S. Didierjean, F. Lapicque, Fuel Cells 2006, 6, 31.

[44] S. Latorrata, P. G. Stampino, C. Cristiani, G. Dotelli, Int. J. Hydrogen Energ. 2015, 40, 14596. 
[45] J. Shan, R. Lin, X. D. Chen, X. Y. Diao, Int. J. Heat Mass Tran. 2018, 127, 1076. 


\section{Tables}

Table 1 - Average static contact angle values with water on MPL and MPS of GDLs obtained with different fluoropolymer-based inks.

\begin{tabular}{ccc}
\hline \multirow{2}{*}{ GDLs } & \multicolumn{2}{c}{ Contact Angle $/^{\circ}$} \\
\cline { 2 - 3 } & MPL side & MPS side \\
\hline PFPE & 165 & 172 \\
PFPE-Hyflon $A D^{\circledR}$ & 168 & 171 \\
Hyflon $A D^{\circledR}$ & 168 & 165 \\
PTFE & 149 a & $148^{\text {a }}$ \\
\hline
\end{tabular}

a. ref. [18]

Table 2 - Maximum power densities in $\mathrm{W} \mathrm{cm}^{-2}$ reached by all the samples at each operating condition.

\begin{tabular}{|c|c|c|c|c|}
\hline GDLs & $60{ }^{\circ} \mathrm{C}, \mathrm{RH}_{\mathrm{c}} 100$ & $60^{\circ} \mathrm{C}, \mathrm{RH}_{\mathrm{c}} 60$ & $80^{\circ} \mathrm{C}, \mathrm{RH}_{\mathrm{c}} 100$ & $80^{\circ} \mathrm{C}, \mathrm{RH}_{\mathrm{c}} 60$ \\
\hline PTFE & 0.422 & 0.417 & 0.440 & 0.402 \\
\hline PFPE & 0.441 & 0.447 & 0.460 & 0.443 \\
\hline PFPE-Hyflon $A D^{\circledR}$ & 0.379 & 0.361 & 0.397 & 0.288 \\
\hline Hyflon $A D^{\circledR}$ & 0.408 & 0.405 & 0.429 & 0.412 \\
\hline
\end{tabular}




\section{Figure Captions}

Figure 1: SEM images of dual-layer GDLs realized with the PFPE-based ink (i) $(A, B)$, the ink containing both peroxidic PFPE and Hyflon $A D^{\circledR}$ (ii) $(C, D)$ and the Hyflon-based ink (iii) $(E, F)$.

Figure 2: Polarization and power density curves obtained for all the samples at: (A) $60{ }^{\circ} \mathrm{C}$ and $\mathrm{RH}(\mathrm{A}-\mathrm{C}) 80-100 \%$, (B) $60{ }^{\circ} \mathrm{C}$ and $\mathrm{RH}$ (A-C) 80-60 \%, (C) $80{ }^{\circ} \mathrm{C}$ and $\mathrm{RH}$ (A-C) 80-100 $\%$, (D) $80^{\circ} \mathrm{C}$ and $\mathrm{RH}(\mathrm{A}-\mathrm{C}) 80-60 \%$.

Figure 3: Selected impedance spectra obtained at low (A) and high (B) current density, at $60^{\circ} \mathrm{C}$ and cathodic $\mathrm{RH} 100 \%$ for samples based on PFPE.

Figure 4: Trend of ohmic resistance as a function of current density for all the samples at: (A) $60{ }^{\circ} \mathrm{C}$ and $\mathrm{RH}(\mathrm{A}-\mathrm{C})$ 80-100\%, (B) $60^{\circ} \mathrm{C}$ and $\mathrm{RH}(\mathrm{A}-\mathrm{C}) 80-60 \%$, (C) $80{ }^{\circ} \mathrm{C}$ and $\mathrm{RH}$ (AC) $80-100 \%$, (D) $80{ }^{\circ} \mathrm{C}$ and $\mathrm{RH}(\mathrm{A}-\mathrm{C}) 80-60 \%$.

Figure 5: Trend of mass transfer resistance as a function of current density for all the samples at: (A) $60{ }^{\circ} \mathrm{C}$ and $\mathrm{RH}(\mathrm{A}-\mathrm{C}) 80-100 \%$, (B) $60{ }^{\circ} \mathrm{C}$ and $\mathrm{RH}$ (A-C) $80-60 \%$, (C) $80^{\circ} \mathrm{C}$ and $\mathrm{RH}(\mathrm{A}-\mathrm{C})$ 80-100 \%, (D) $80^{\circ} \mathrm{C}$ and $\mathrm{RH}(\mathrm{A}-\mathrm{C}) 80-60 \%$.

Figure 6: Polarization curves obtained every $100 \mathrm{~h}$ of constant current durability tests for PFPE (A) and PTFE (B) GDLs. Operating condition: $80^{\circ} \mathrm{C}$ and $80-100 \%(A-C)$.

Figure 7: Polarization curves obtained upon $500 \mathrm{~h}$ of constant current durability tests and accelerated stress tests for PFPE and PTFE GDLs. Operating condition: $80^{\circ} \mathrm{C}$ and $80-100$ $\%(A-C)$. 
Figure 8: Trend of ohmic resistance (A) and diffusion resistance (B) as a function of current density upon $500 \mathrm{~h}$ of constant current durability tests and accelerated stress tests for PFPE and PTFE GDLs. 

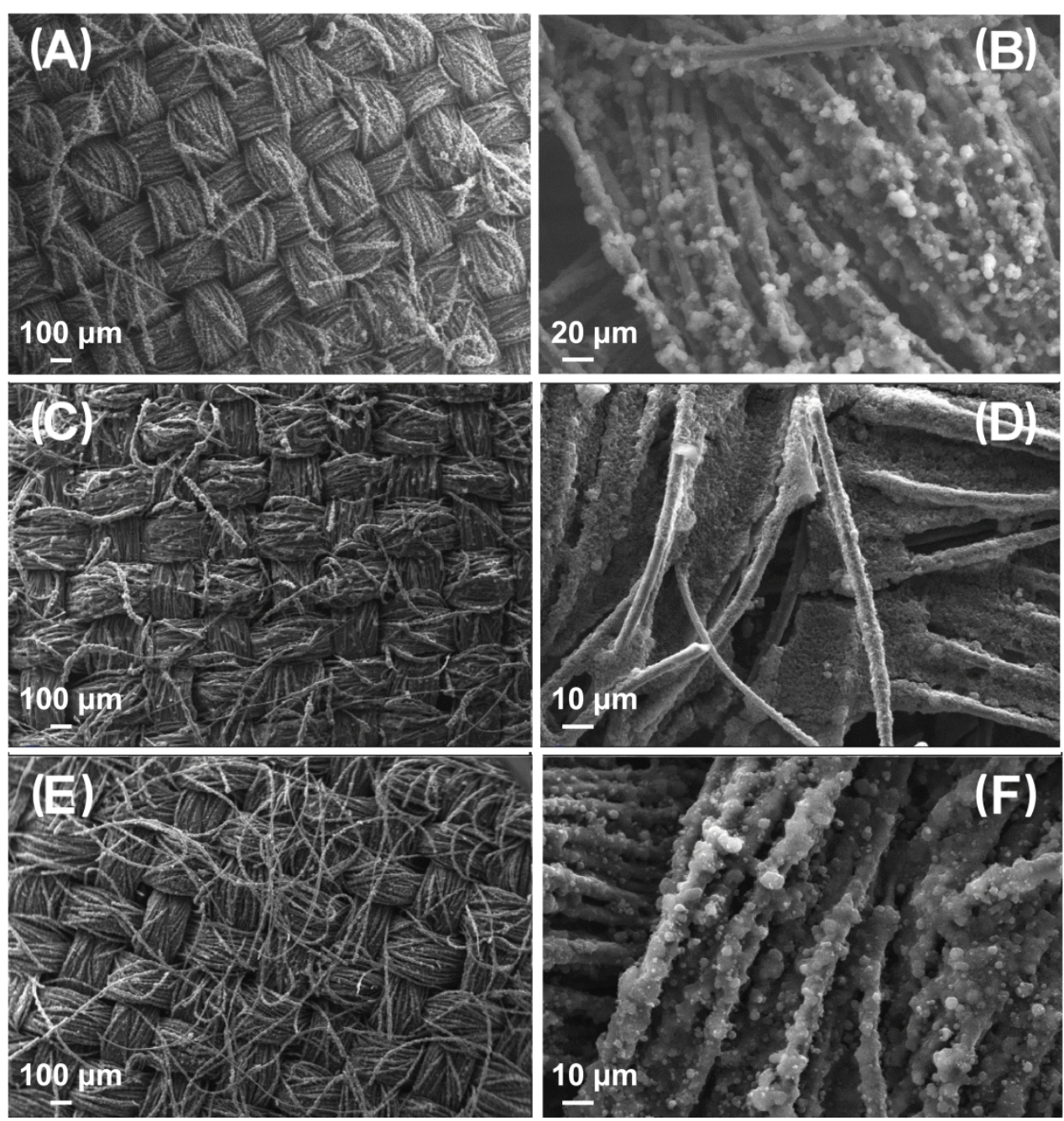

Figure 1: SEM images of dual-layer GDLs realized with the PFPE-based ink (i) (A, B), the ink containing both peroxidic PFPE and Hyflon $A D \otimes($ ii) $(C, D)$ and the Hyflon-based ink (iii) (E, F). 


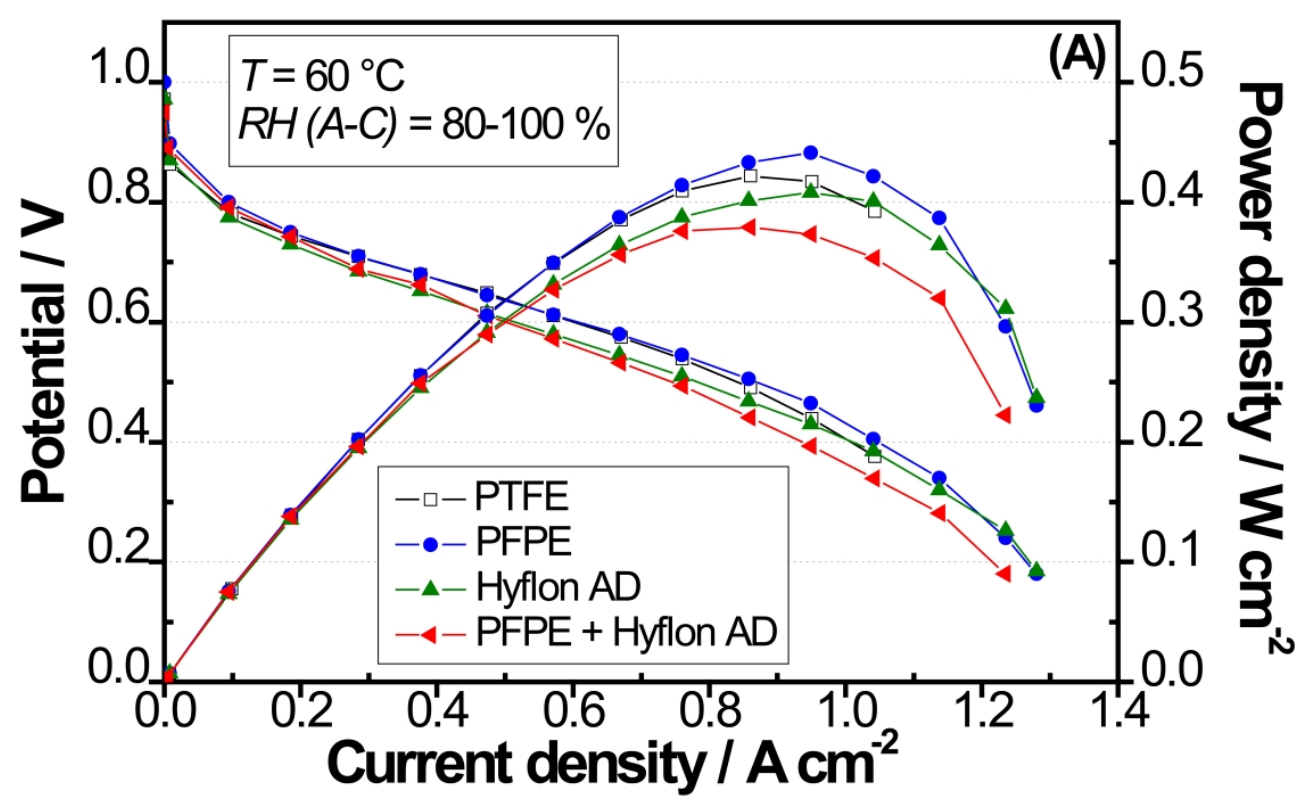

Figure 2A: Polarization and power density curves obtained for all the samples at $60^{\circ} \mathrm{C}$ and $\mathrm{RH}(\mathrm{A}-\mathrm{C}) 80-100$ 


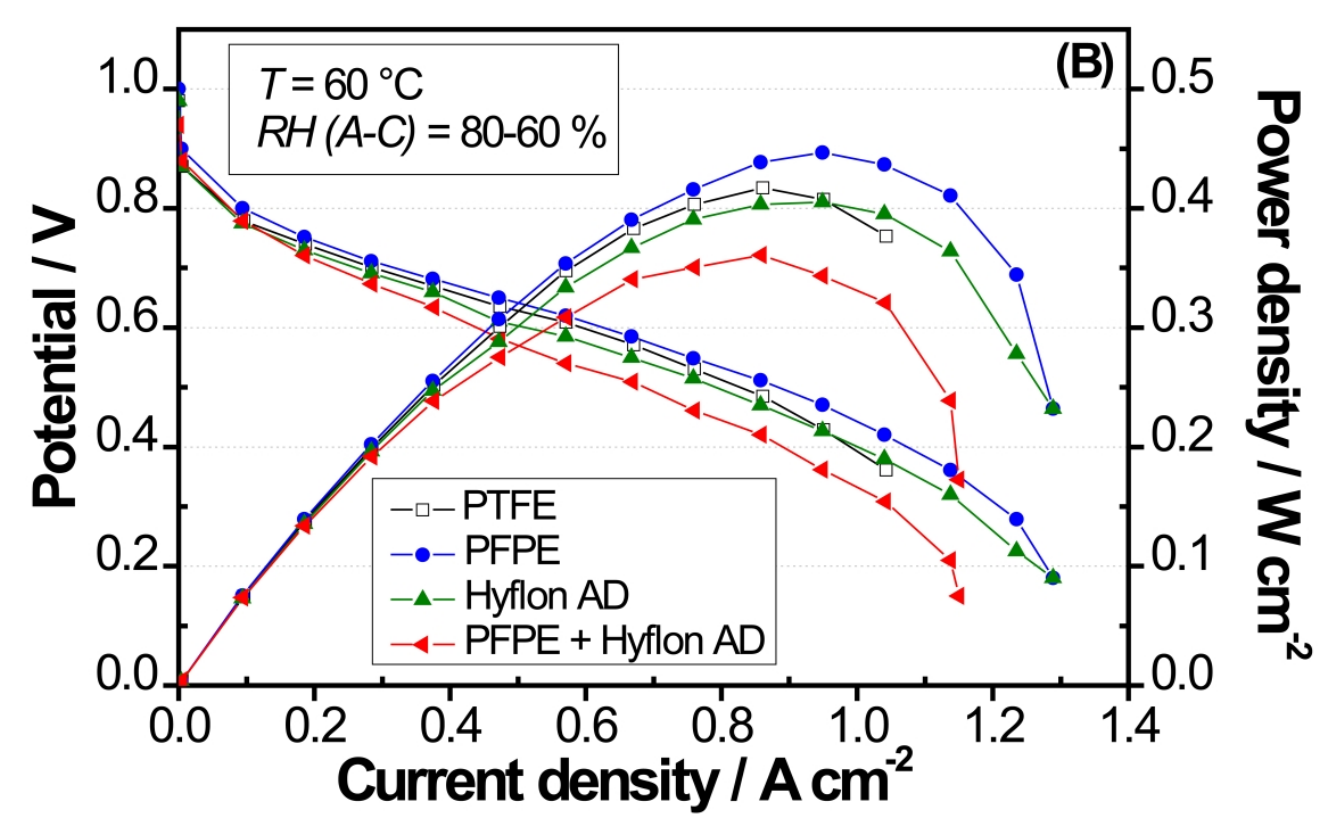

Figure 2B: Polarization and power density curves obtained for all the samples at $60^{\circ} \mathrm{C}$ and $\mathrm{RH}(\mathrm{A}-\mathrm{C}) 80-60$ $\%$ 


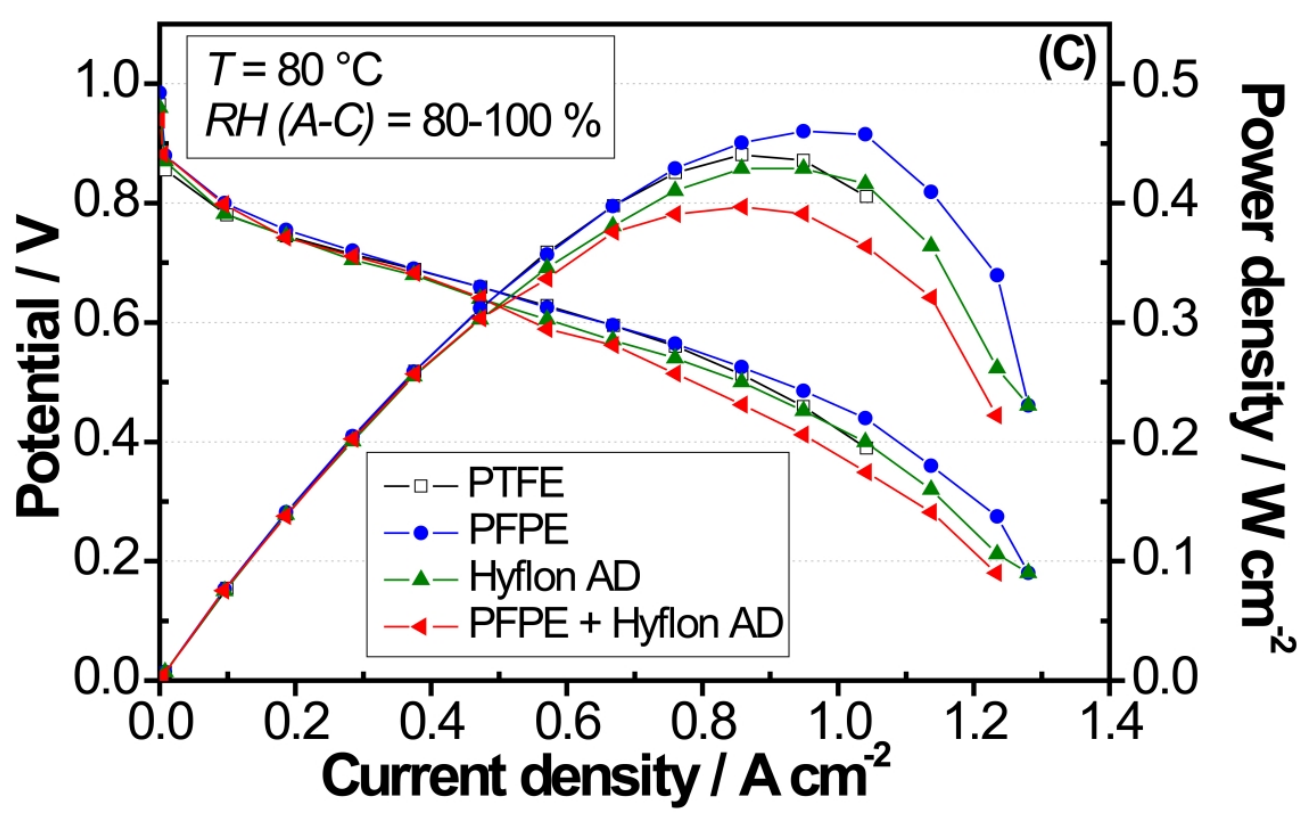

Figure 2C: Polarization and power density curves obtained for all the samples at $80^{\circ} \mathrm{C}$ and $\mathrm{RH}(\mathrm{A}-\mathrm{C}) 80-100$ 


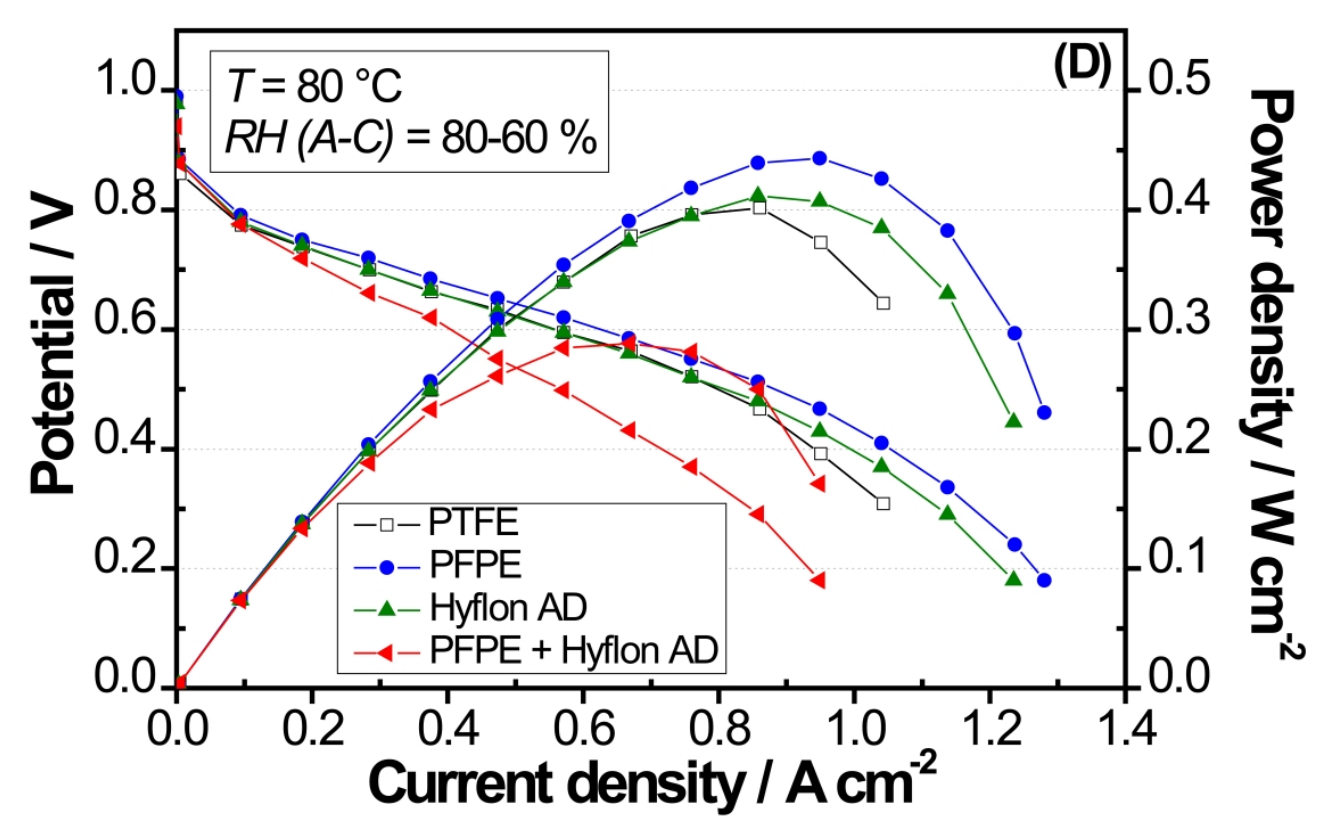

Figure 2D: Polarization and power density curves obtained for all the samples at $80^{\circ} \mathrm{C}$ and $\mathrm{RH}(\mathrm{A}-\mathrm{C}) 80-60$ $\%$ 


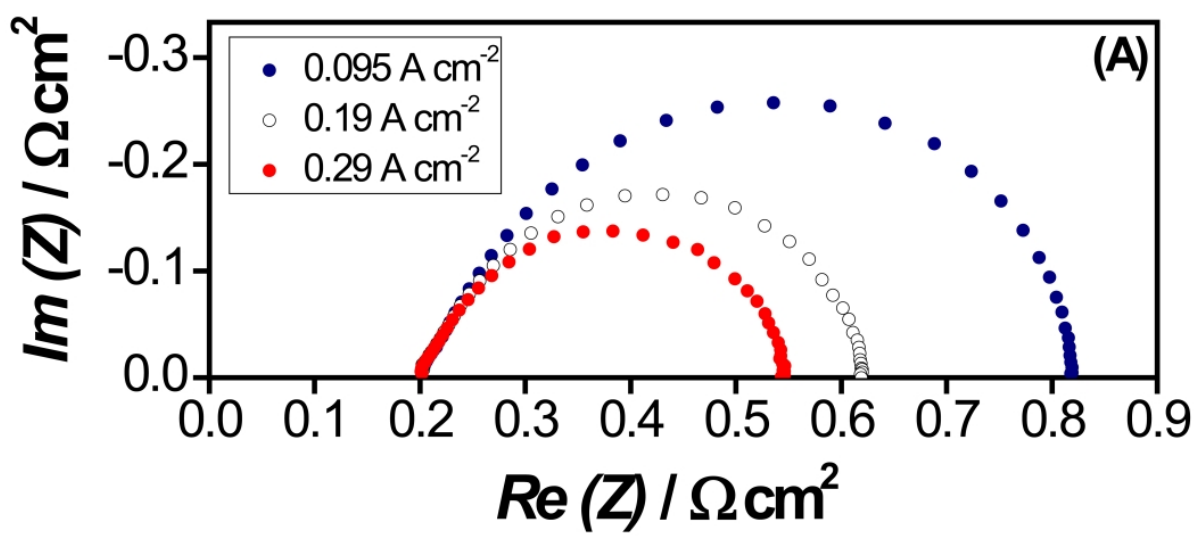

Figure 3A: Selected impedance spectra obtained at low current density, at $60{ }^{\circ} \mathrm{C}$ and cathodic $\mathrm{RH} 100 \%$ for samples based on PFPE. 


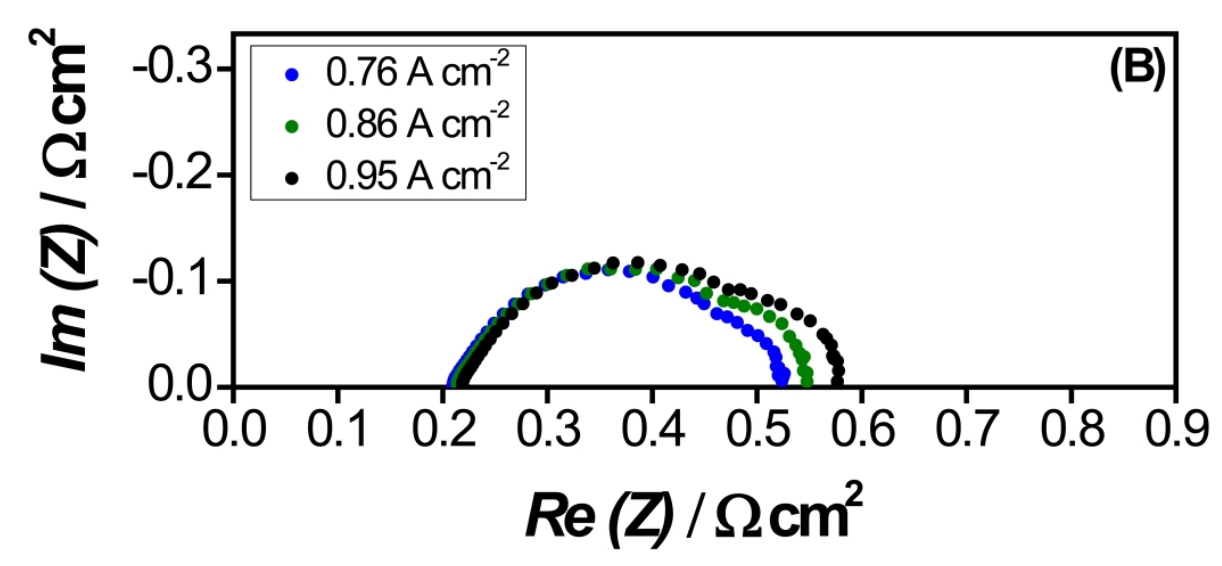

Figure 3B: Selected impedance spectra obtained at high current density, at $60{ }^{\circ} \mathrm{C}$ and cathodic $\mathrm{RH} 100 \%$ for samples based on PFPE. 


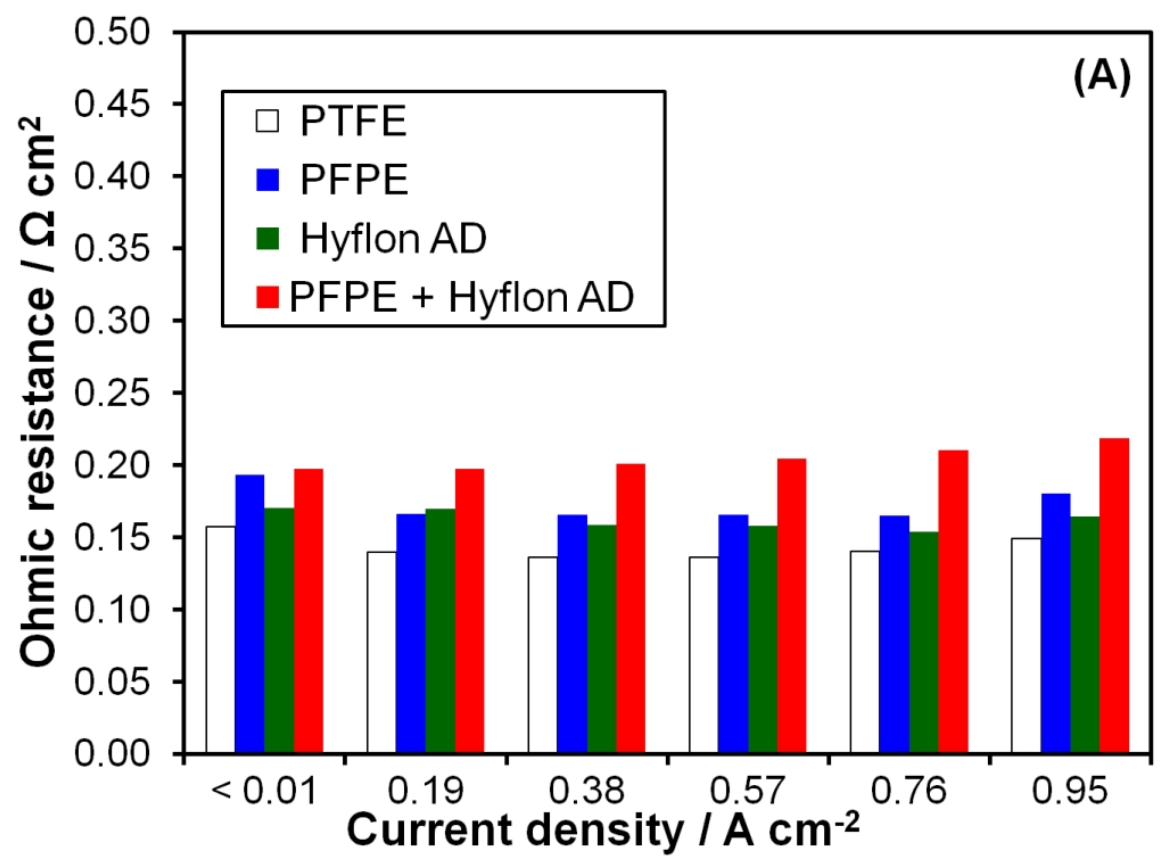

Figure 4A: Trend of ohmic resistance as a function of current density for all the samples a $60{ }^{\circ} \mathrm{C}$ and RH (AC) $80-100 \%$. 


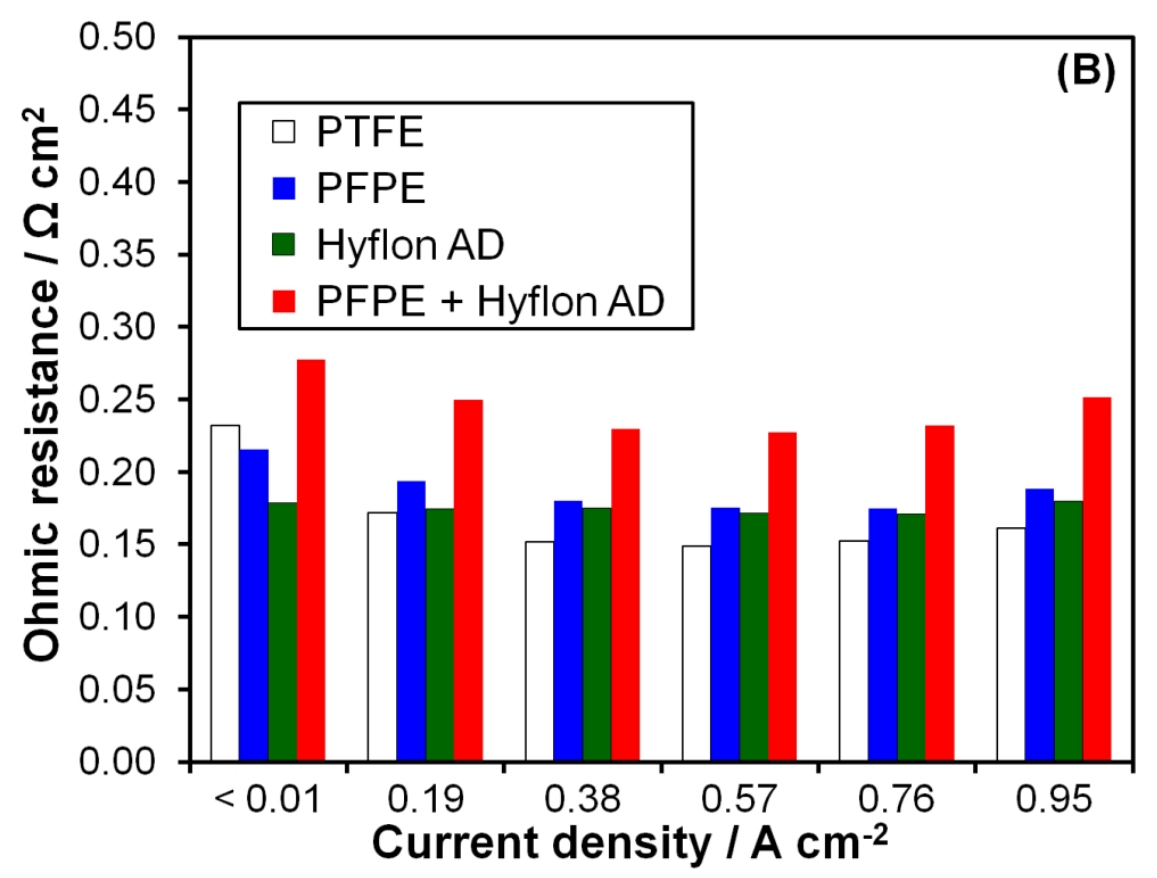

Figure 4B: Trend of ohmic resistance as a function of current density for all the samples at $60^{\circ} \mathrm{C}$ and $\mathrm{RH}$ (AC) $80-60 \%$. 


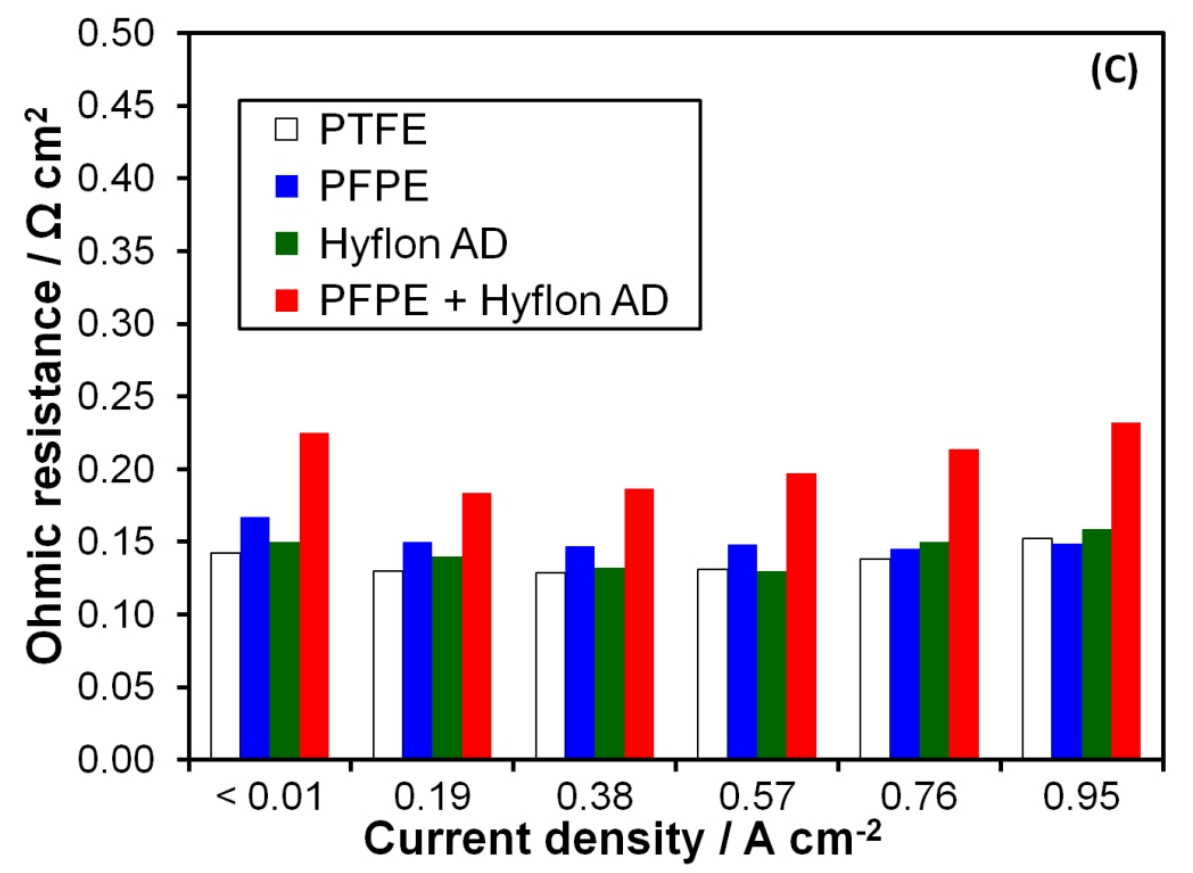

Figure 4C: Trend of ohmic resistance as a function of current density for all the samples at $80^{\circ} \mathrm{C}$ and $\mathrm{RH}$ (AC) $80-100 \%$. 


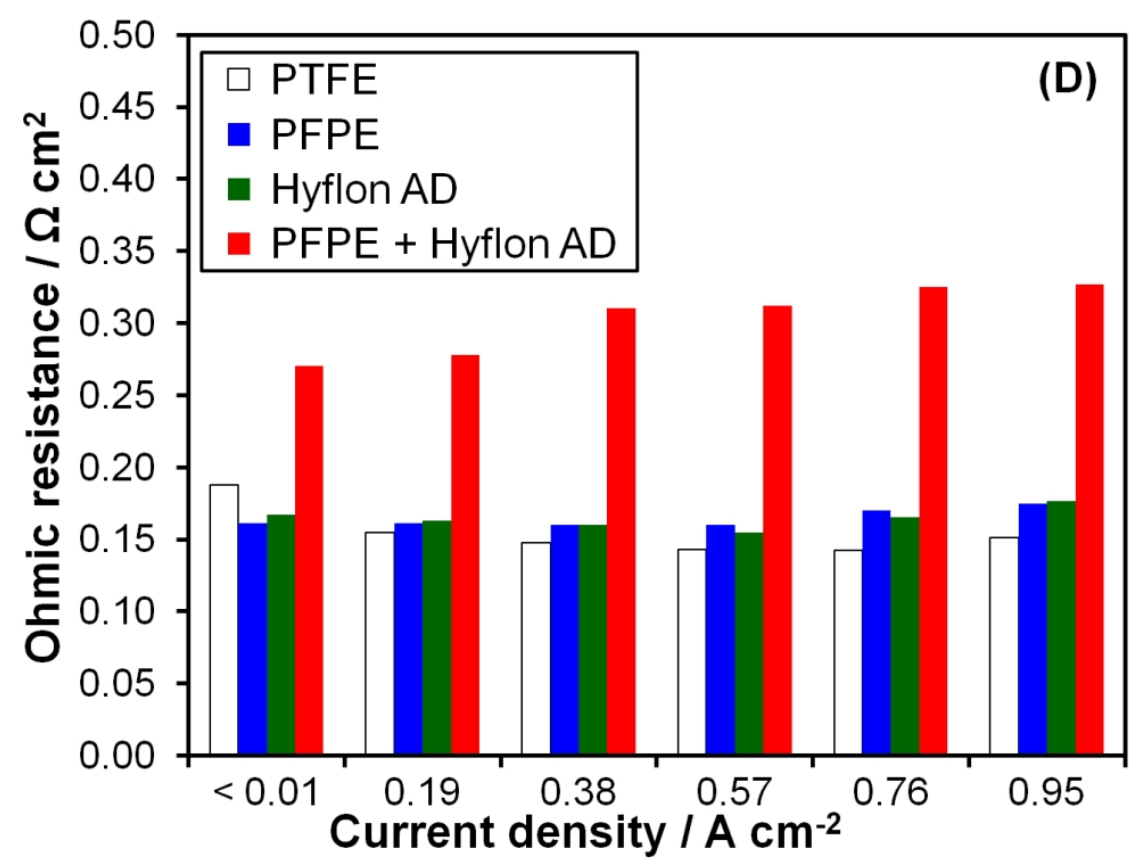

Figure 4D: Trend of ohmic resistance as a function of current density for all the samples a $80{ }^{\circ} \mathrm{C}$ and $\mathrm{RH}$ (AC) $80-60 \%$. 


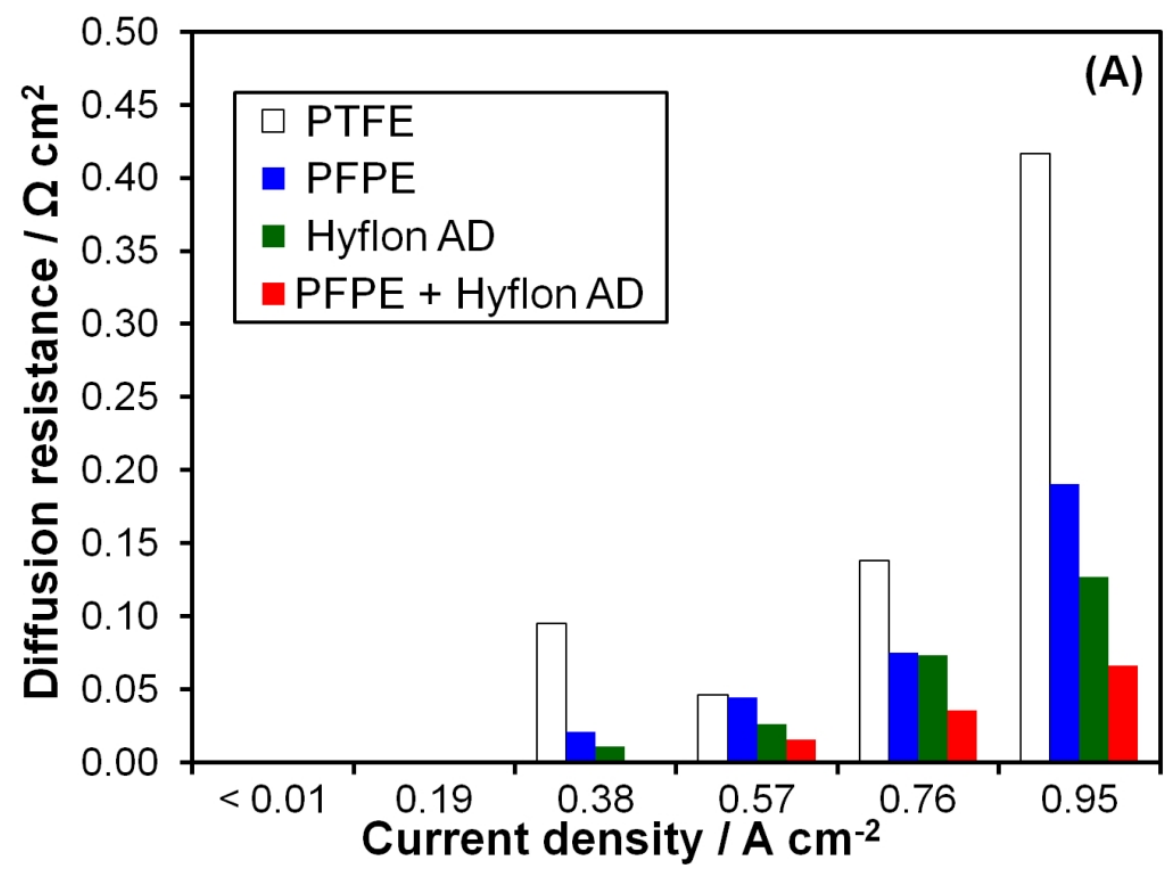

Figure 5A: Trend of mass transfer resistance as a function of current density for all the samples at $60{ }^{\circ} \mathrm{C}$ and $\mathrm{RH}(\mathrm{A}-\mathrm{C})$ 80-100\%. 


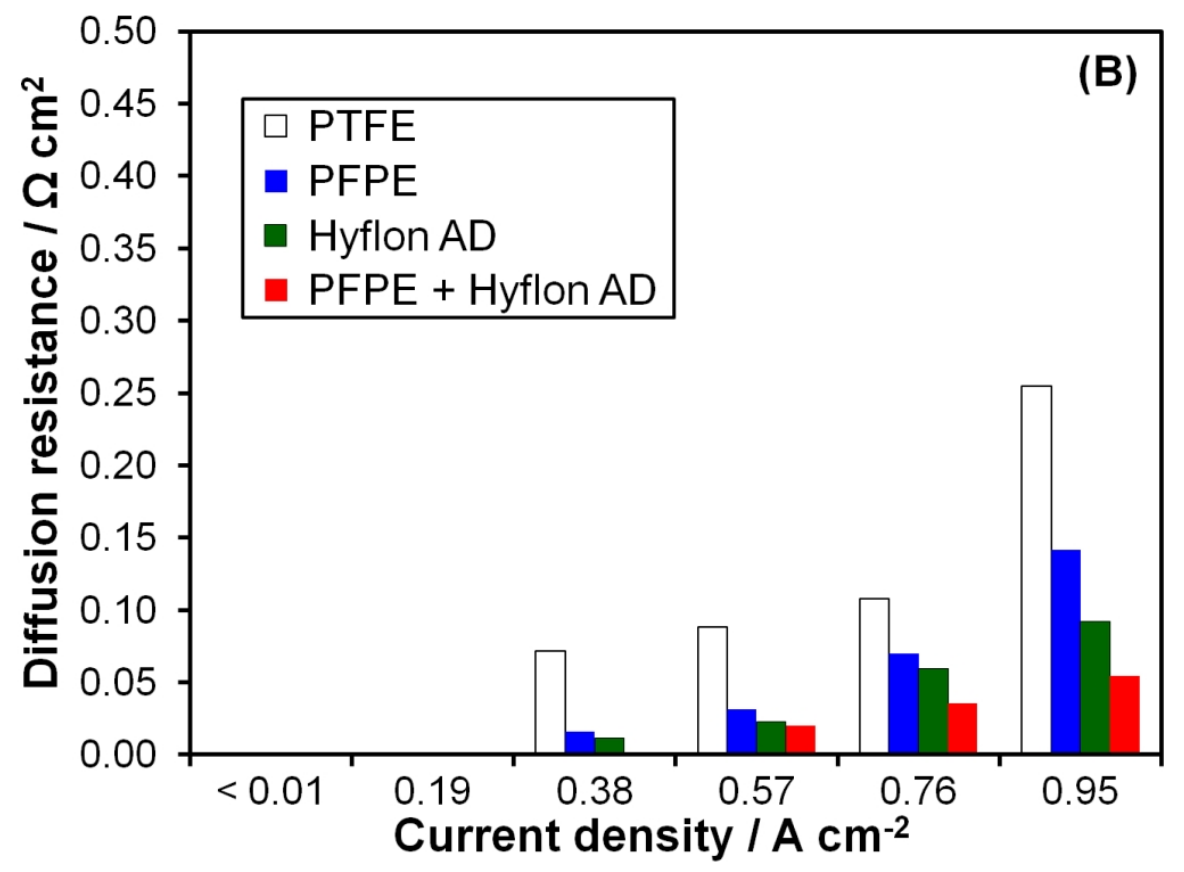

Figure 5B: Trend of mass transfer resistance as a function of current density for all the samples at $60{ }^{\circ} \mathrm{C}$ and RH (A-C) 80-60\%. 


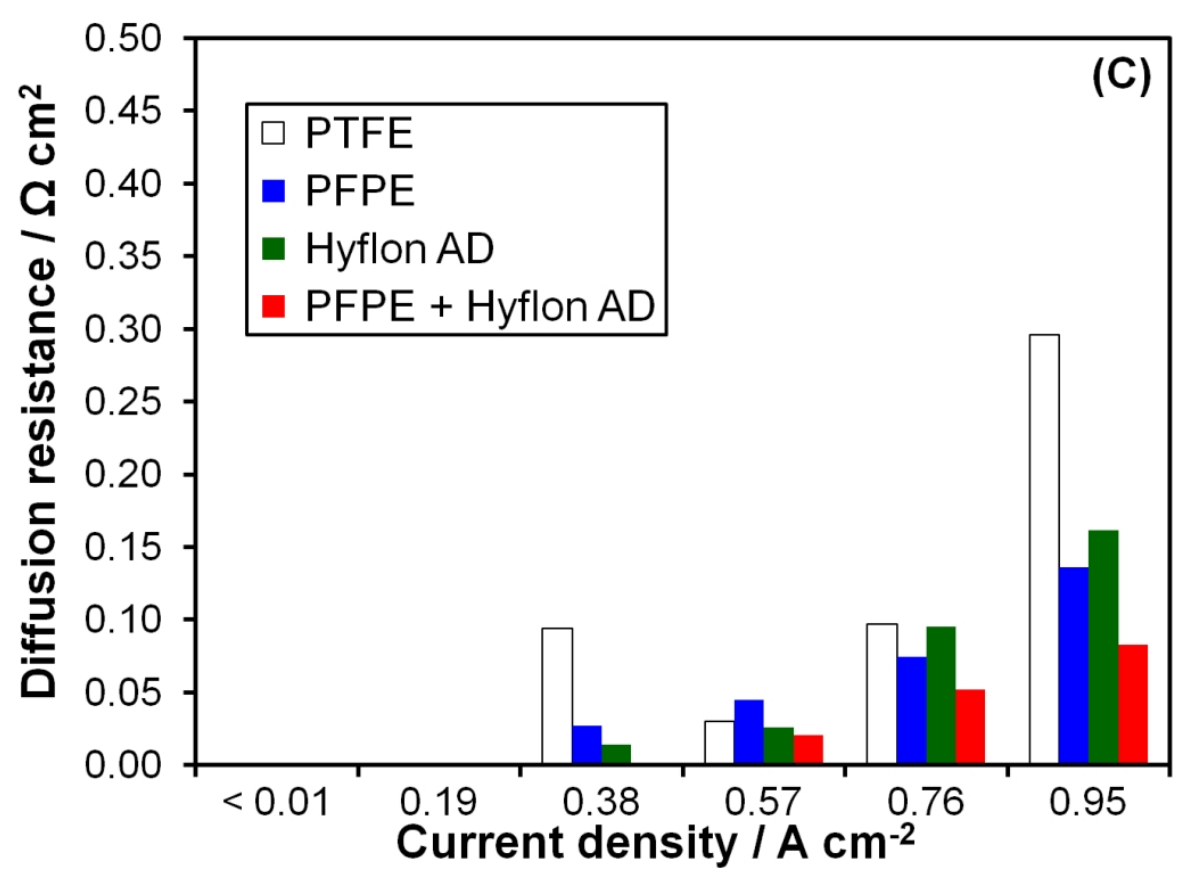

Figure 5C: Trend of mass transfer resistance as a function of current density for all the samples at $80{ }^{\circ} \mathrm{C}$ and $\mathrm{RH}(\mathrm{A}-\mathrm{C}) \mathrm{80}-100 \%$. 


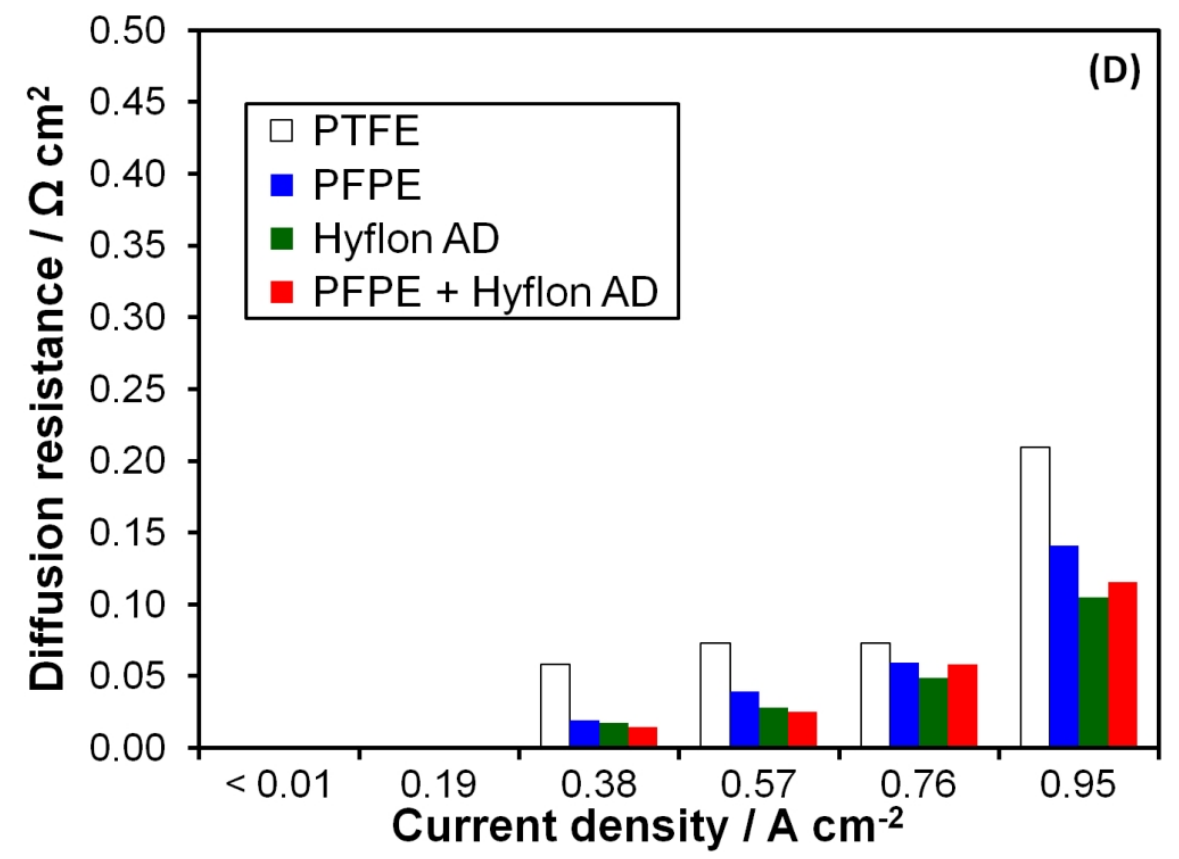

Figure 5D: Trend of mass transfer resistance as a function of current density for all the samples at $80{ }^{\circ} \mathrm{C}$ and $\mathrm{RH}(\mathrm{A}-\mathrm{C}) \mathrm{80}-60 \%$. 


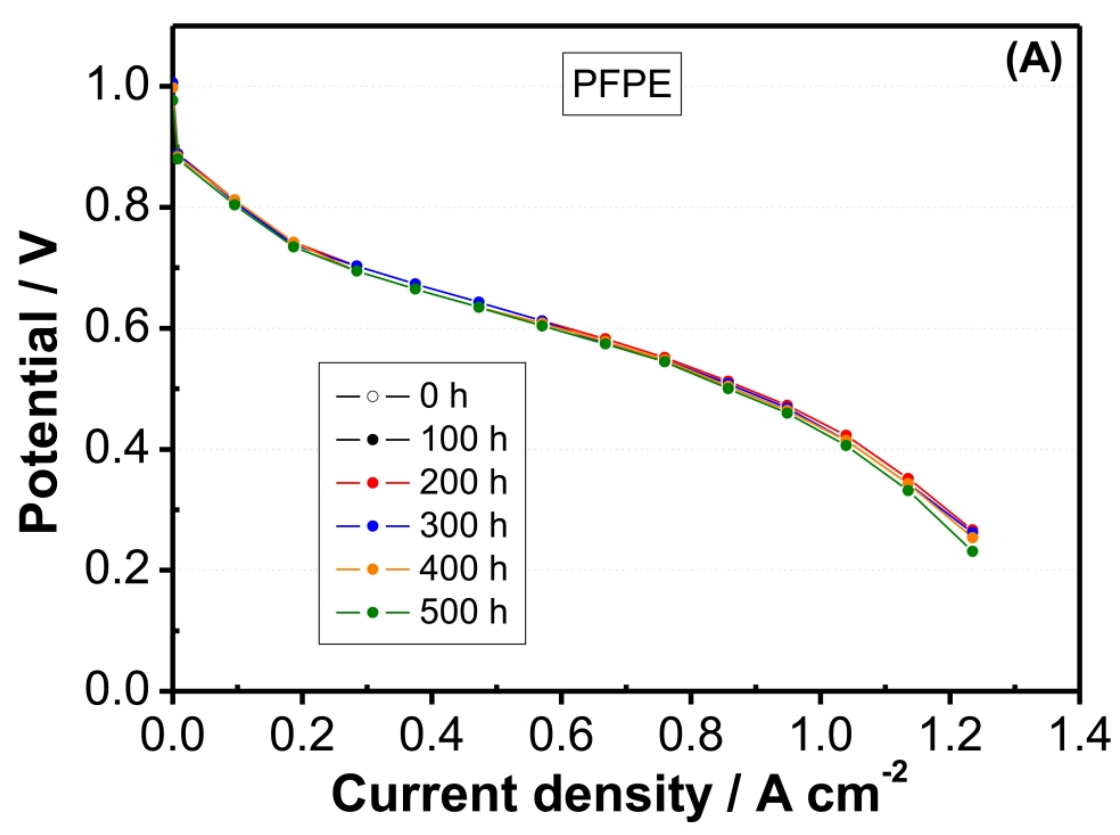

Figure 6A: Polarization curves obtained every $100 \mathrm{~h}$ of constant current durability tests for PFPE GDL. Operating condition: $80^{\circ} \mathrm{C}$ and $80-100 \%(\mathrm{~A}-\mathrm{C})$. 


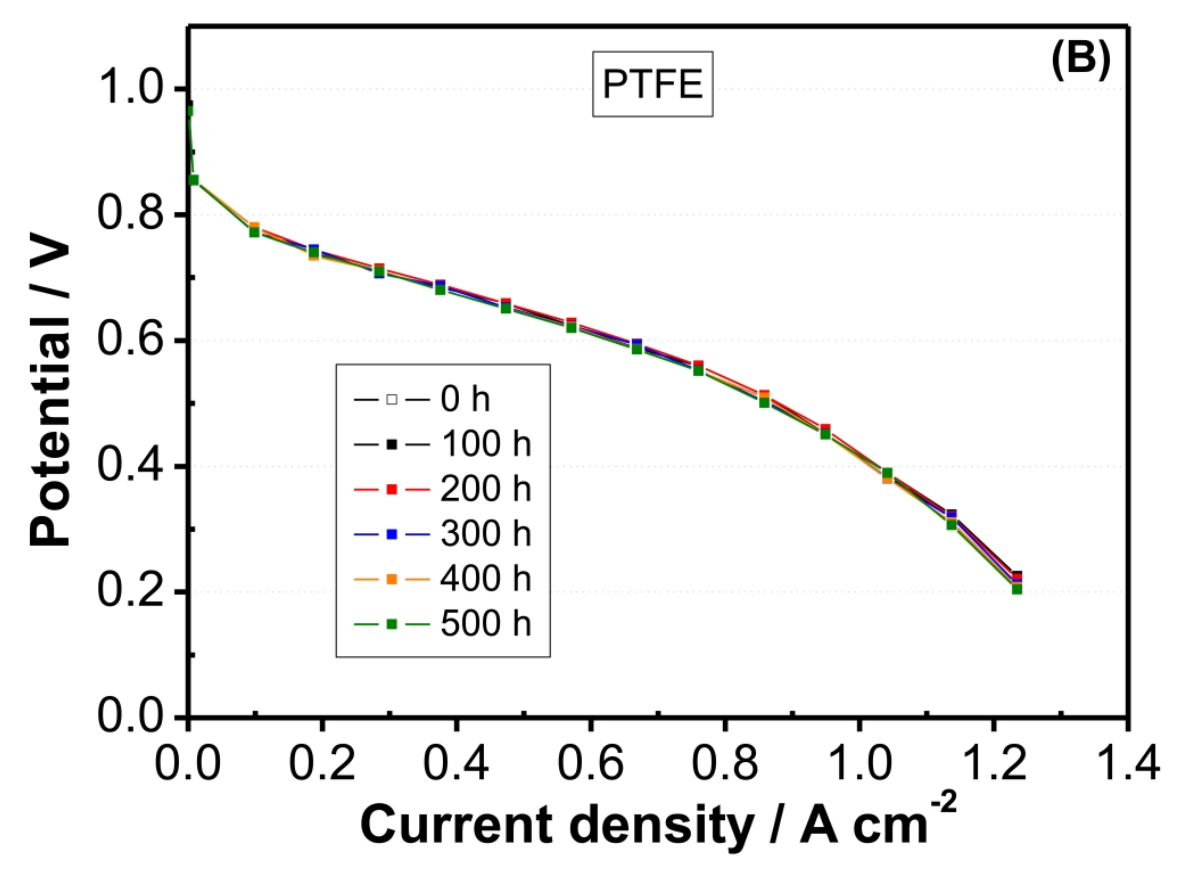

Figure 6B: Polarization curves obtained every $100 \mathrm{~h}$ of constant current durability tests for PTFE GDL. Operating condition: $80{ }^{\circ} \mathrm{C}$ and $80-100 \%(\mathrm{~A}-\mathrm{C})$. 


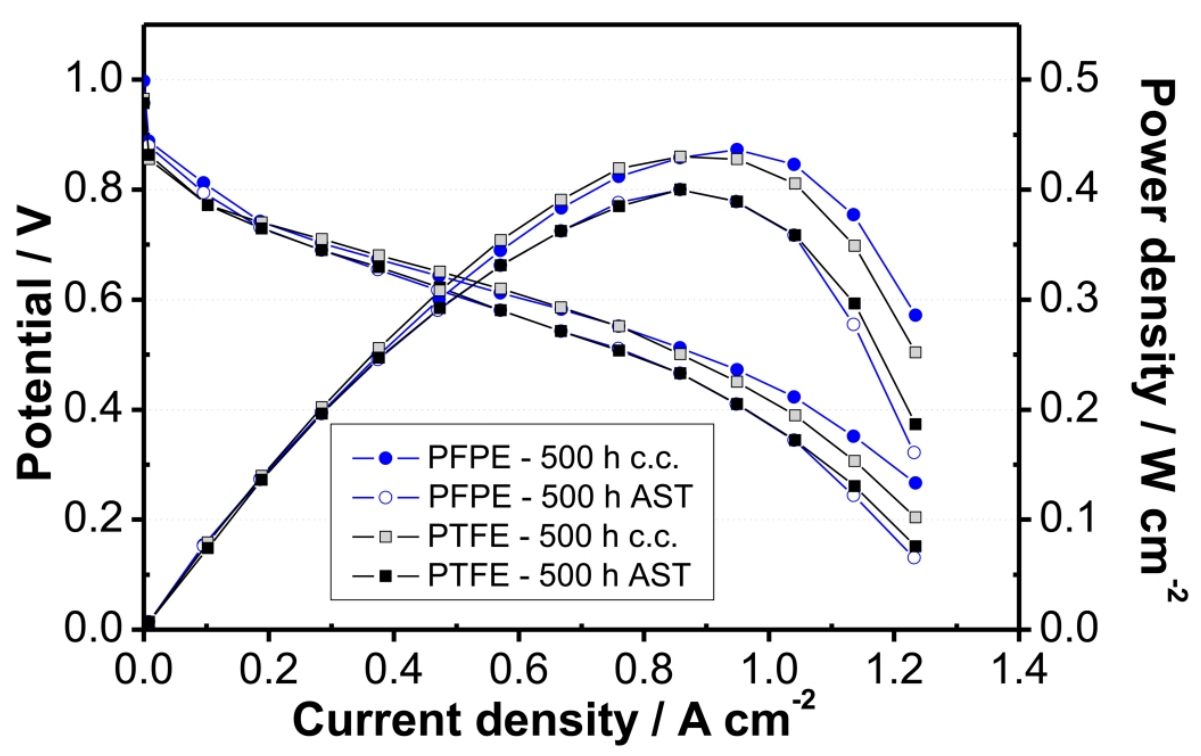

Figure 7: Polarization curves obtained upon $500 \mathrm{~h}$ of constant current durability tests and accelerated stress tests for PFPE- and PTFE-based GDLs. Operating condition: $80^{\circ} \mathrm{C}$ and 80-100 \% (A-C).

$198 \times 125 \mathrm{~mm}(600 \times 600 \mathrm{DPI})$ 


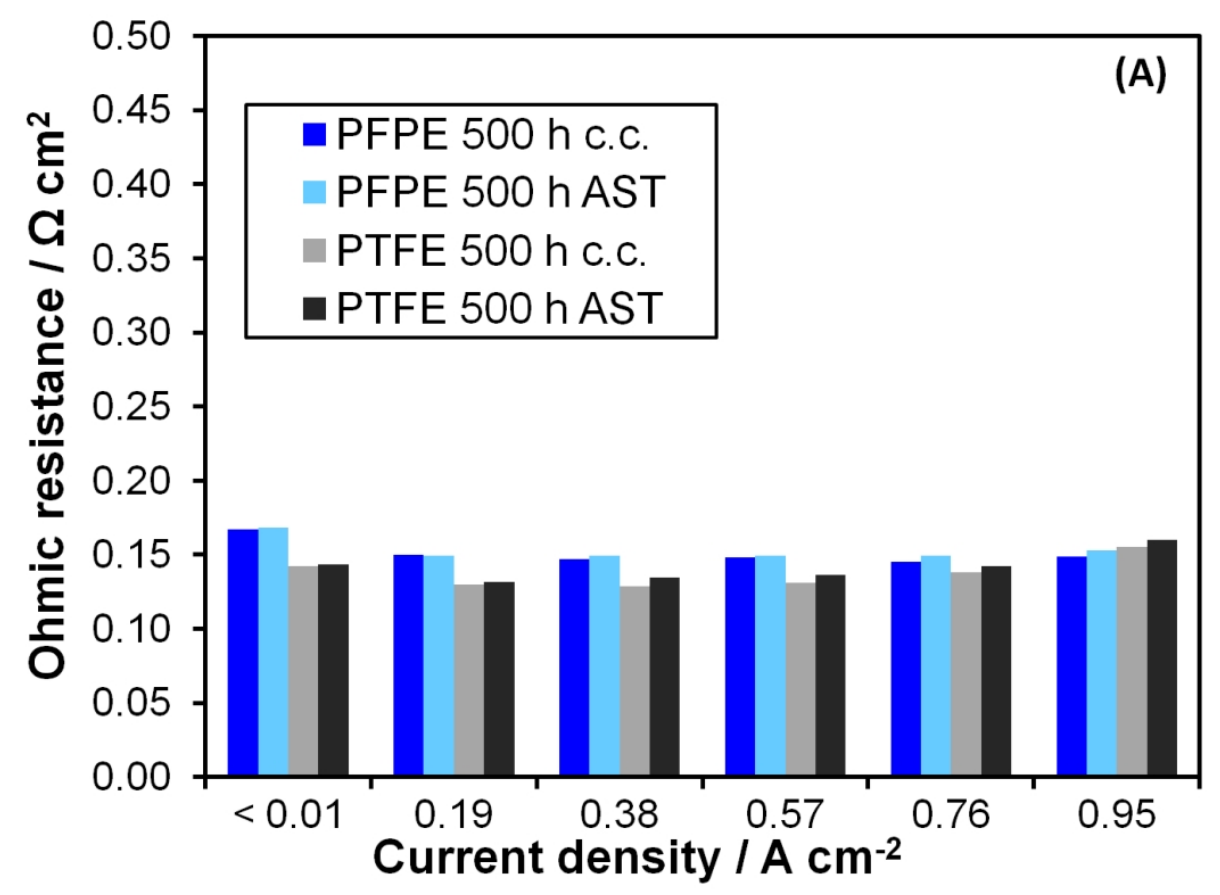

Figure 8A: Trend of ohmic resistance as a function of current density upon $500 \mathrm{~h}$ of constant current durability tests and accelerated stress tests for PFPE and PTFE GDLs. 


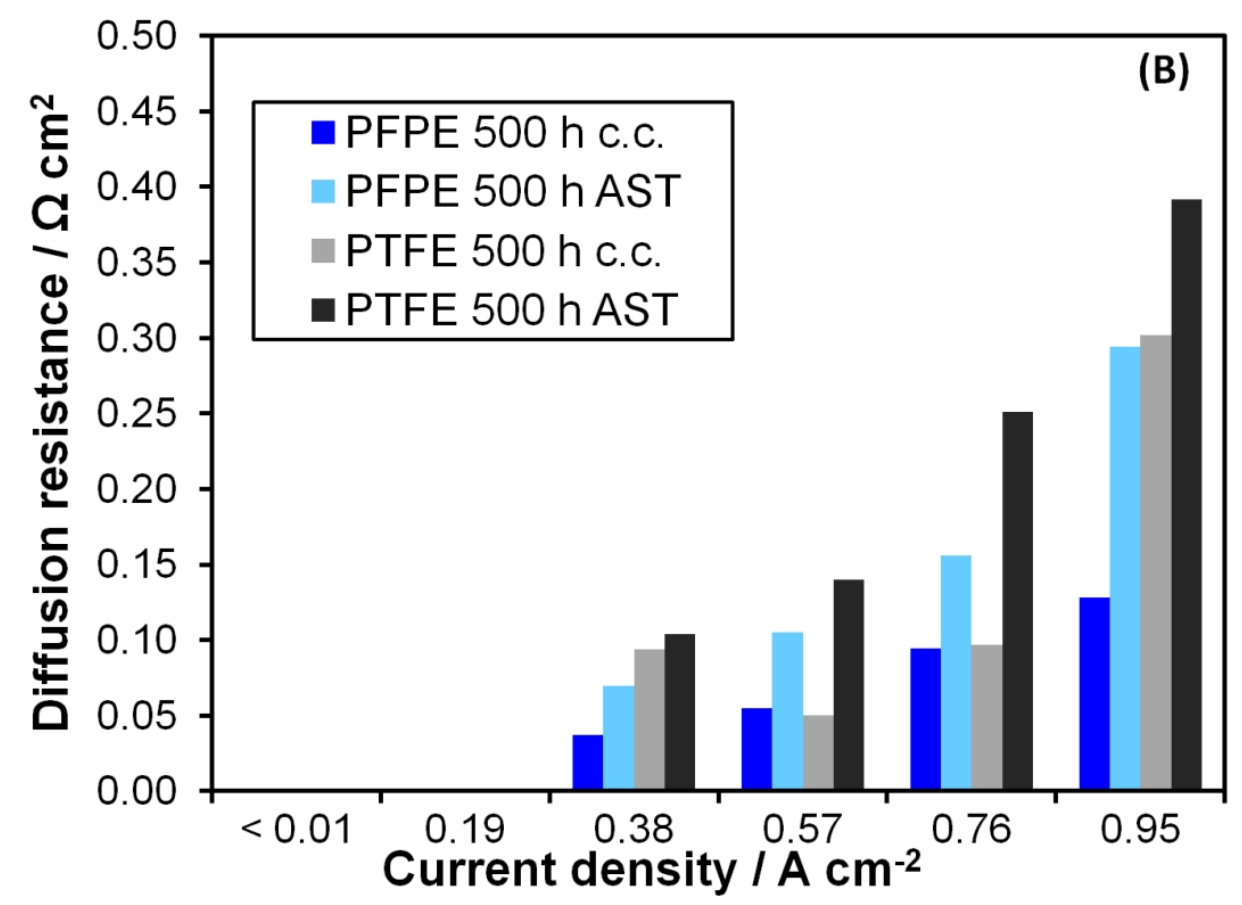

Figure 8B: Trend of diffusion resistance as a function of current density upon $500 \mathrm{~h}$ of constant current durability tests and accelerated stress tests for PFPE and PTFE GDLs. 


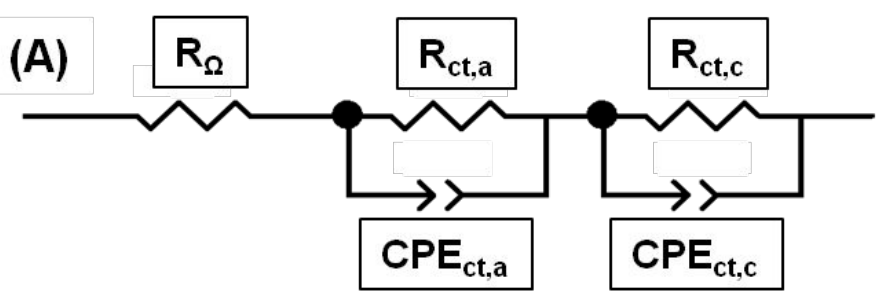

Supplementary Material - Equivalent circuits used for fitting EIS data at low current densities $\left(<0.35 \mathrm{~A} \mathrm{~cm}^{-2}\right)(\mathrm{A})$ and at high current densities $\left(>0.35 \mathrm{~A} \mathrm{~cm}^{-2}\right)(\mathrm{B}) ; \mathrm{R}_{\Omega}$ : overall ohmic resistance (or HFR, high frequency resistance), $R_{c t, a}$ : anodic charge transfer resistance, $R_{c t, c}$ : cathodic charge transfer resistance, $R_{m t}$ : mass transfer resistance, $\mathrm{CPE}_{\mathrm{ct}, \mathrm{a}}$ : constant phase element for the anodic charge transfer, $\mathrm{CPE}_{\mathrm{ct}, \mathrm{c}}:$ constant phase element for the cathodic charge transfer, $\mathrm{CPE}_{\mathrm{mt}}$ : constant phase element for the mass transfer. 
Supplementary Material - Equivalent circuits used for fitting EIS data at low current densities $(<0.35 \mathrm{~A} \mathrm{~cm}-$ 2) $(A)$ and at high current densities ( $>0.35 \mathrm{~A} \mathrm{~cm}-2)(B) ; R \Omega$ : overall ohmic resistance (or HFR, high frequency resistance), Rct,a: anodic charge transfer resistance, Rct, $c$ : cathodic charge transfer resistance, Rmt: mass transfer resistance, CPEct,a: constant phase element for the anodic charge transfer, CPEct,c: constant phase element for the cathodic charge transfer, CPEmt: constant phase element for the mass transfer.

$171 \times 114 \mathrm{~mm}(300 \times 300 \mathrm{DPI})$ 